\title{
Neurological Alterations in Cognitive Impairment
}

\author{
Parastoo Barati Dowom $^{1,2}$, Marzieh Darvishi ${ }^{3 *}$, Khadijeh Heidarbeigi ${ }^{3}$ \\ ${ }^{1}$ Shefa Neuroscience Research Center, Khatam Alanbia Hospital, Tehran, Iran
}

${ }^{2}$ Department of Physiology, Faculty of Sciences, Qom Branch, Islamic Azad University, Qom, Iran

${ }^{3}$ Department of Anatomy, Faculty of Medicine, Ilam University of Medical Sciences, Ilam, Iran

\section{A BSTRACT}

Introduction: Cognitive functions contains the processing of thoughts, memory, and attention. Deficiency in one or all of the abovementioned functions may cause behavioral changes that commonly is known as cognitive disorders. The most common cognitive disorders are Alzheimer's disease and Parkinson's disease. These diseases, in addition to the destruction of cognitive behavior (memory, learning and attention) are associated with: disability of movement, a common symptom of cognitive impairment. These diseases are accompanied by many histological alterations, such as extracellular amyloid- $\beta$ (A $\beta$ ) peptidecontaining plaques, tau protein, astrocytic gliosis, and reactive micoglia. This histological changes are linked with the abnormalities of the receptors. The pathological effect in the structures and functions of neural receptors leads to dysregulation of intracellular pathways and cellular signals. Conclusion: The intracellular signaling cascade regulated calcium ion flux, membrane excitability, and activation of various receptors. Neurotransmitters play: an important role in facilitating the processes of learning and memory. Impairment of these: receptors may cause cognitive changes.

\section{Key words:}

1. Alzheimer Disease

2. Parkinson Disease

3. Cognition

*Corresponding Author: Marzieh Darvishi

E-mail: Marzidarvish@yahoo.com

doi: 10.18869/acadpub.shefa.4.4.99 


\title{
تغييرات عصبى در اختلال شناختى
}

\author{
يرستو براتى دوم ‘'، مرضيه درويشى "*:، خديجه حيدربيكى" \\ 'مركز تحقيقات علوم اعصاب شفا، بيمارستان خاتمالانبياء، تهران، ايران

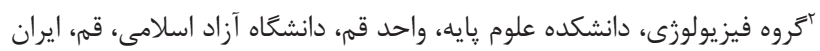

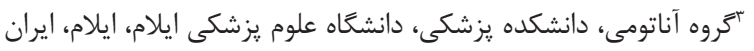

كليد وازهها:

ا. بيمارى آلزايمر

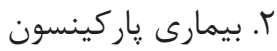

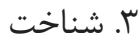

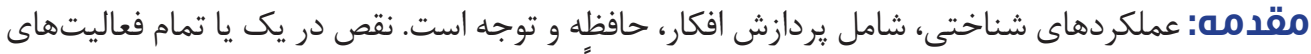

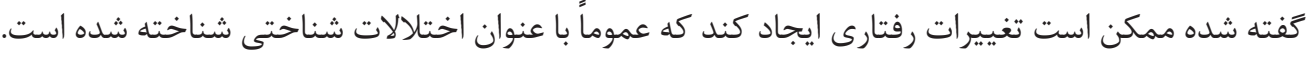

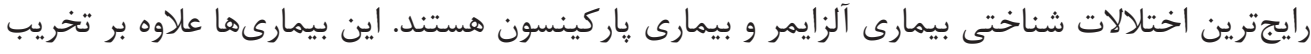

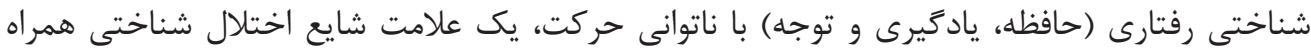

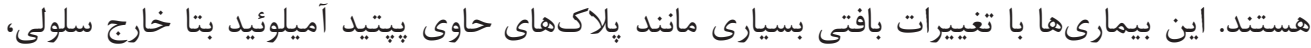

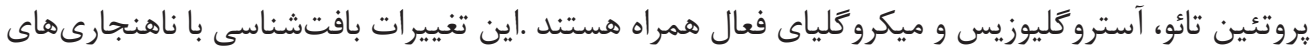

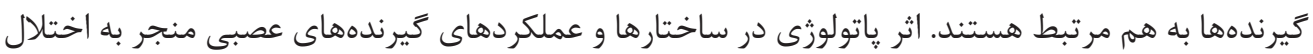

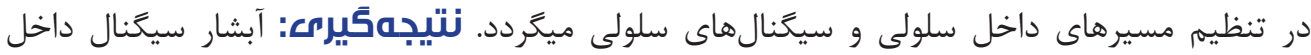

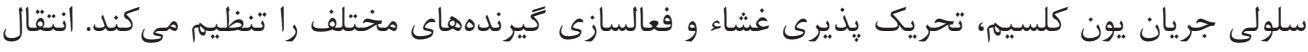

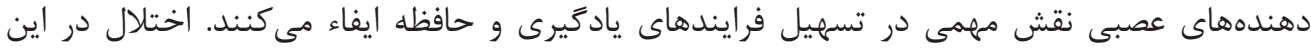
كيرندها ممكن است تغييرات شناختى ايجاد كند.

" نويسنده مسئول: مرضيه درويشى آدرس الكترونيكى: . Marzidarvish@yahoo.com 


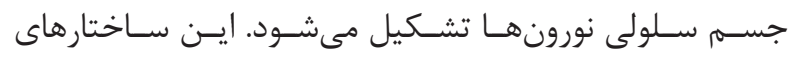

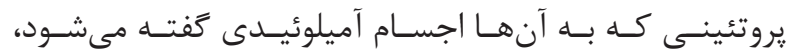

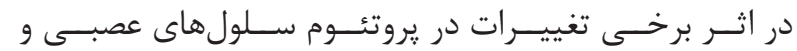

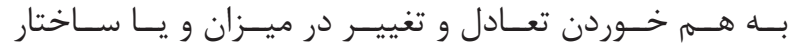

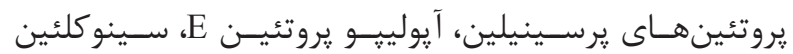

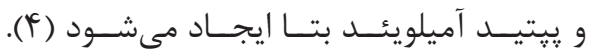

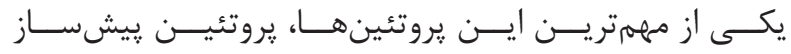

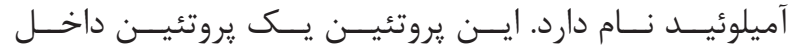

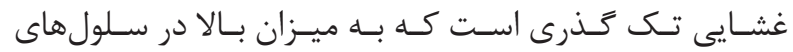

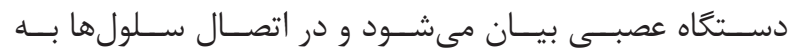

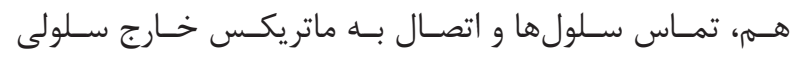

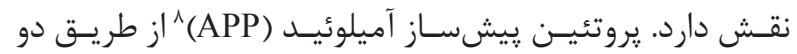

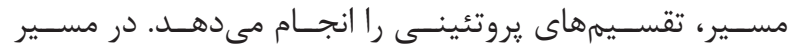

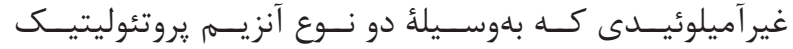

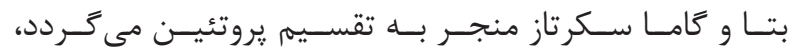

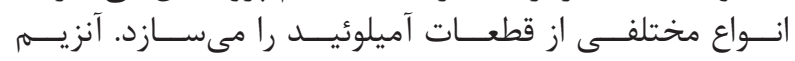

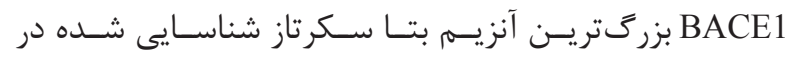

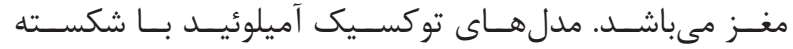

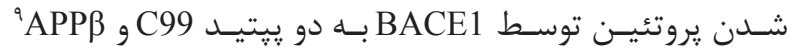

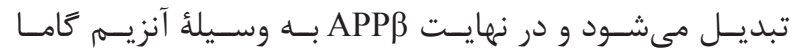

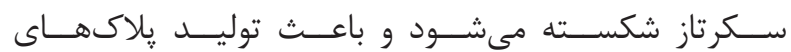

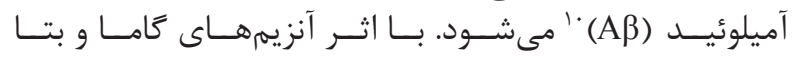

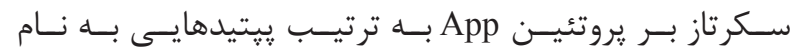

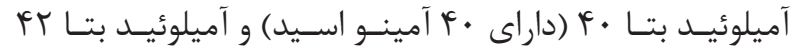

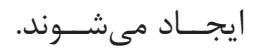

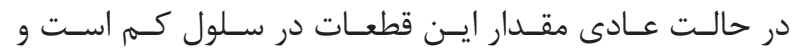

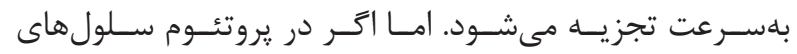

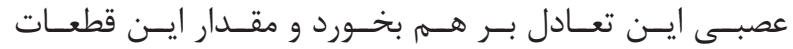

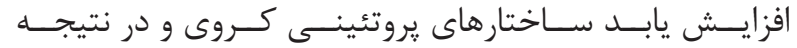

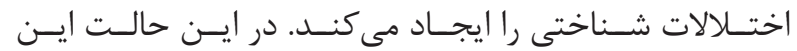

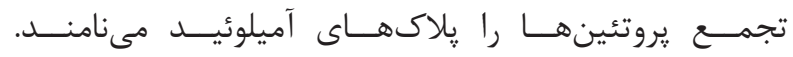

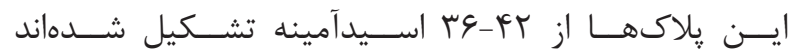

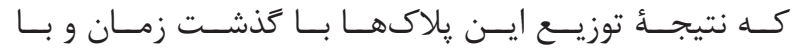

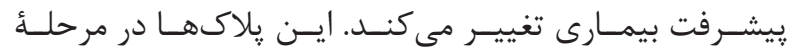

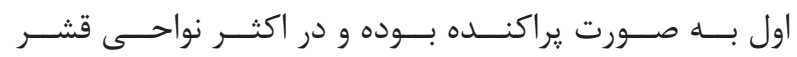

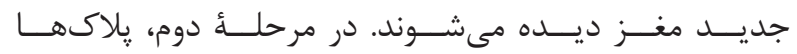

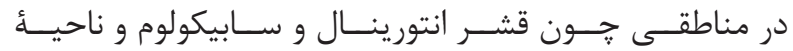

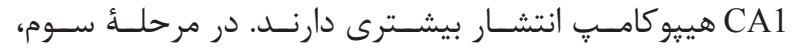

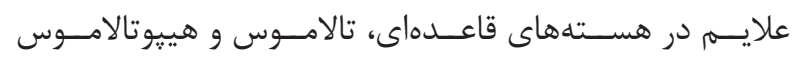

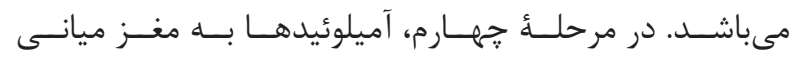

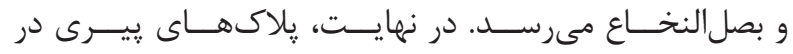

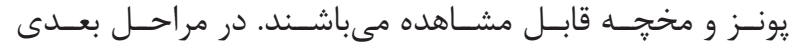

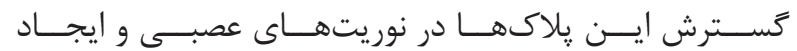

${ }^{1}$ International classification of diseases

${ }^{2}$ Delirium

${ }^{3}$ Dementia

${ }^{4}$ Amenstic disorders

${ }^{5}$ Neurotransmitters
مقدمه

تعريف اختلالات شناختى و انواع آن

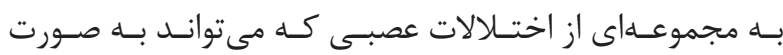

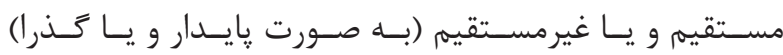

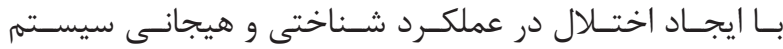

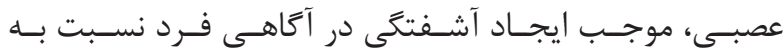

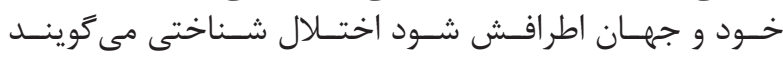

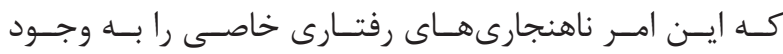

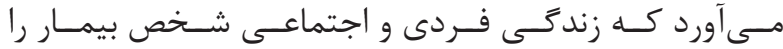

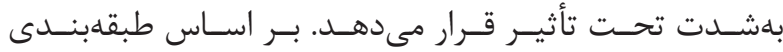

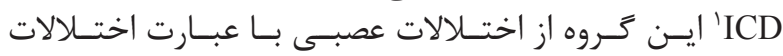

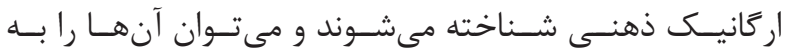

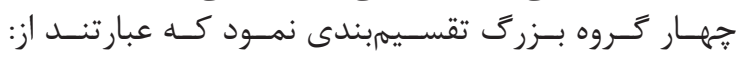

$$
\text { زوال عقلَّفتى }
$$

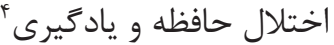

اختلال حافظهٔ ناشى از بيمارىهاى دافيكر

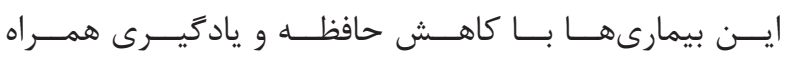

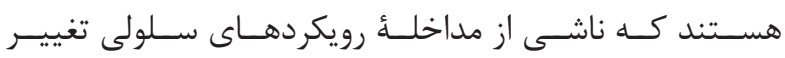

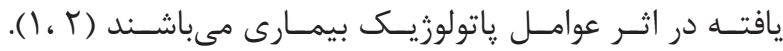

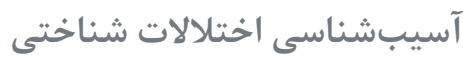

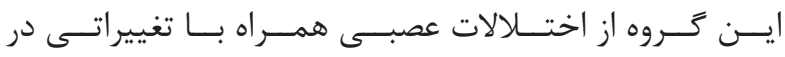

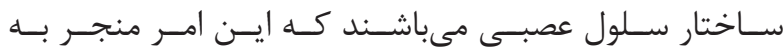

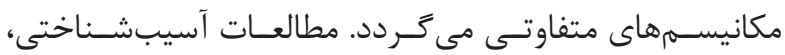

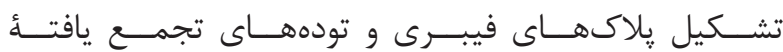

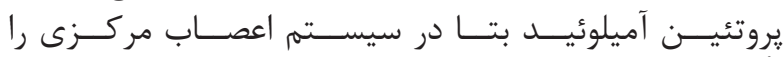

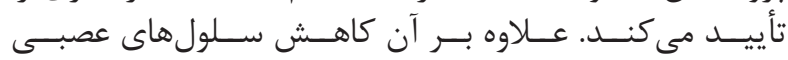

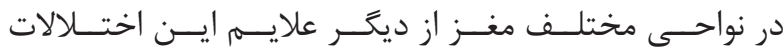

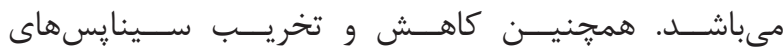

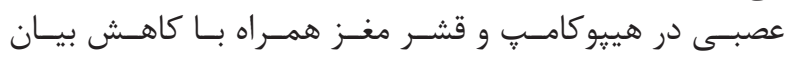

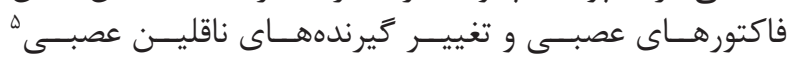

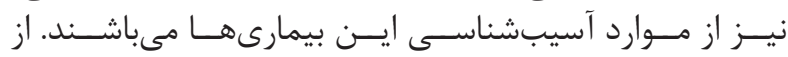

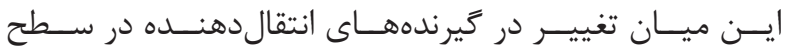

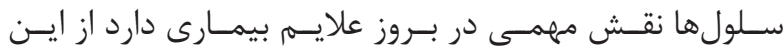

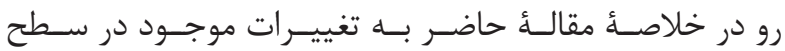

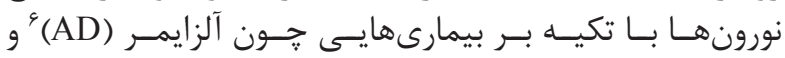

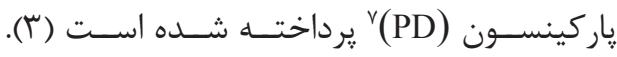
الف) يلاكهاى بتا آميلوئيد

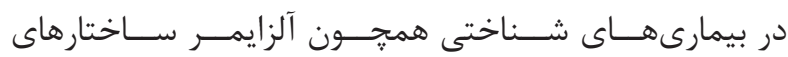

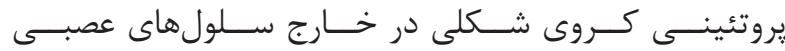

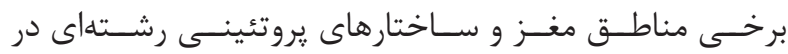

\footnotetext{
${ }^{6}$ Alzheimer's disease

${ }^{7}$ Parkinson's disease

${ }^{8}$ Amyloid precursor protein

${ }^{9}$ Amyloid beta protein precursor

${ }^{10}$ Amyloid beta
} 


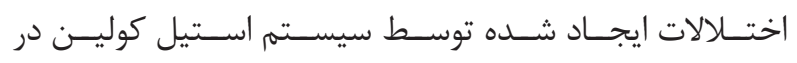

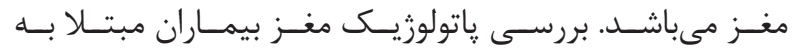

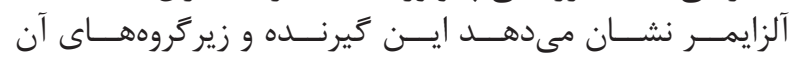

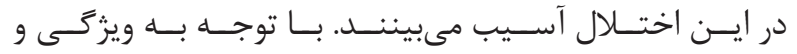

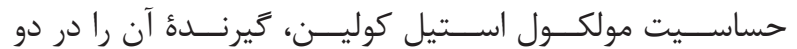

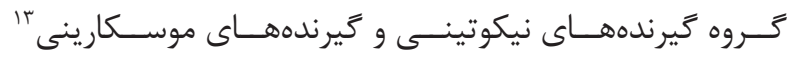

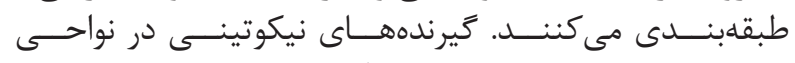

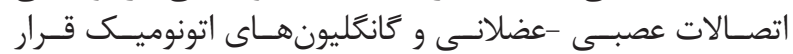

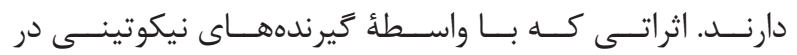

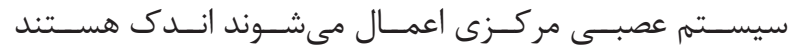

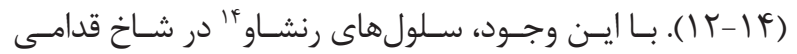

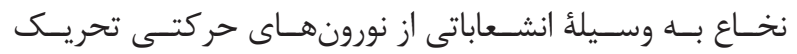

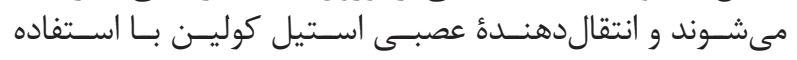

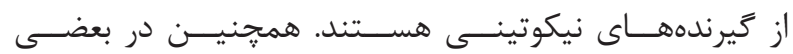

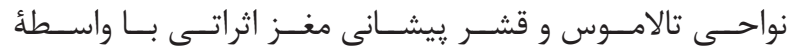

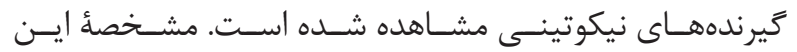

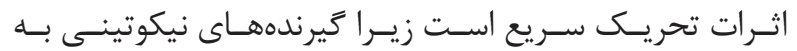

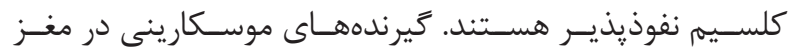

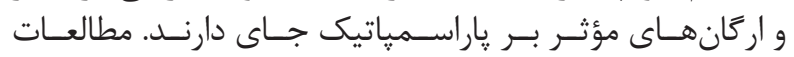

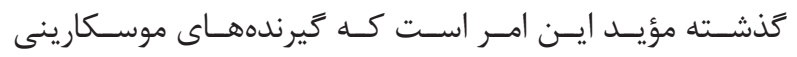

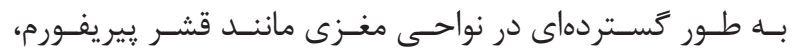

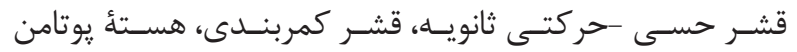

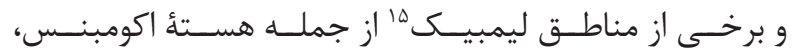

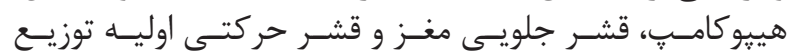

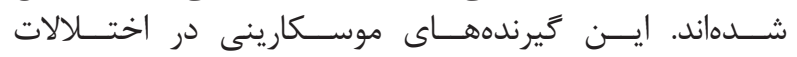

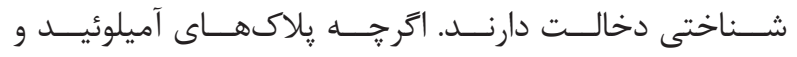

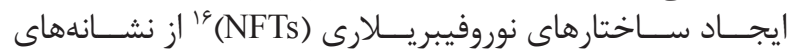

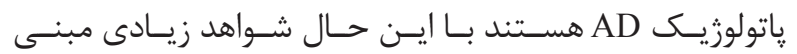

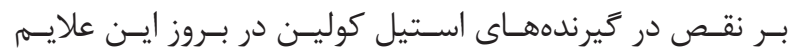

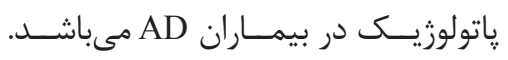

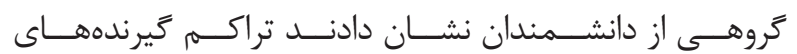

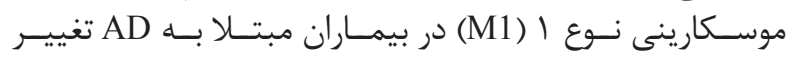

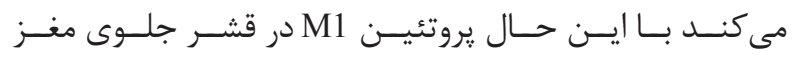

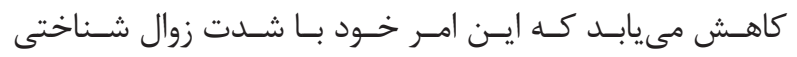

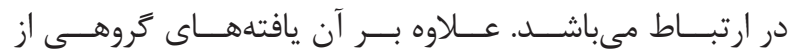

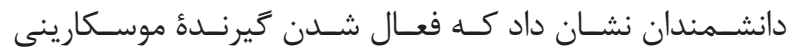

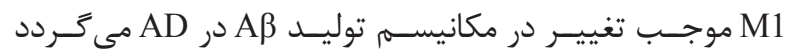

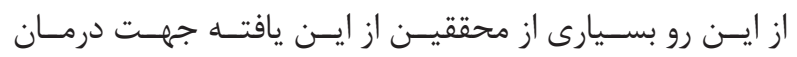

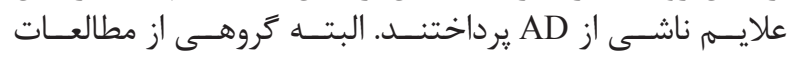

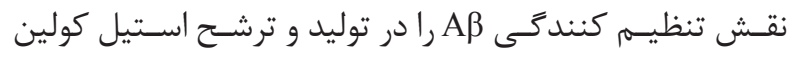

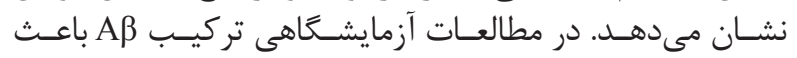

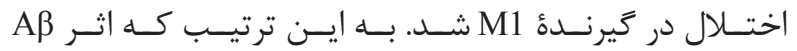

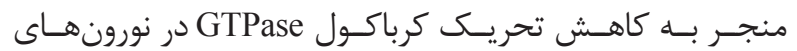

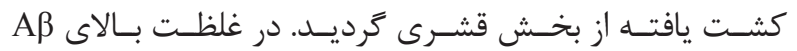

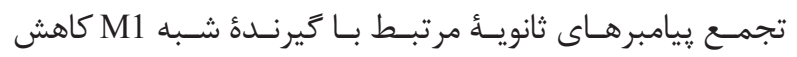

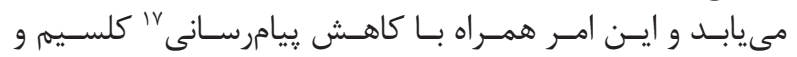

${ }^{11}$ Nuclear factor E2-related factor 2

${ }^{12}$ Antioxidant response element

${ }^{13}$ Muscarinic receptors

${ }^{14}$ Renshaw cells

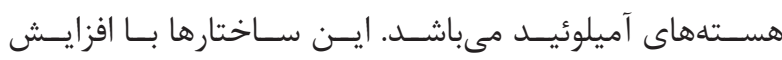

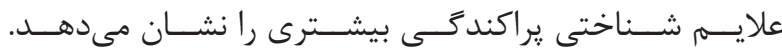

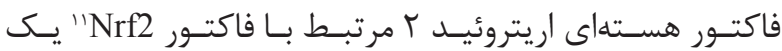

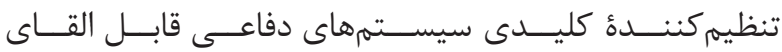

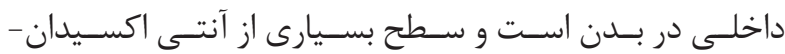

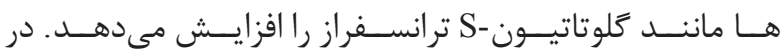

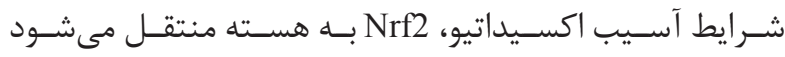

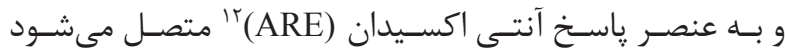

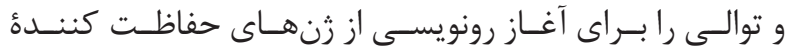

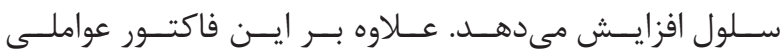

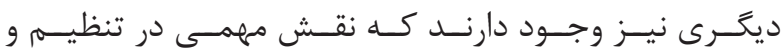

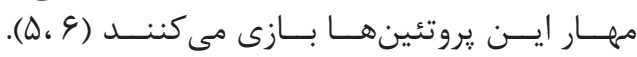
ب) بروتئين هاى فيبر يلارى Tau

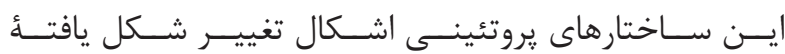

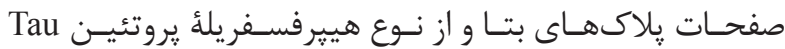

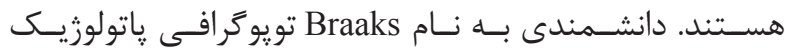

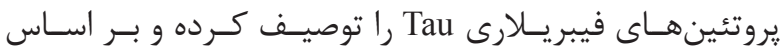

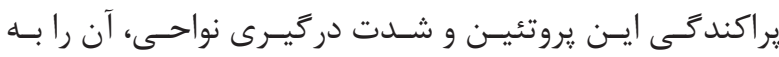

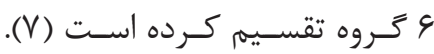

ڤ) تغييرات كيرندهاى انتقال دهندة عصبى در اختلالات شناختى تغيبر

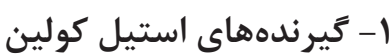

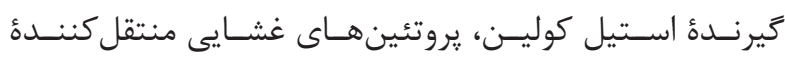

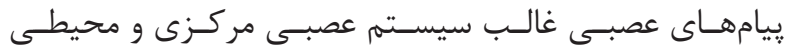

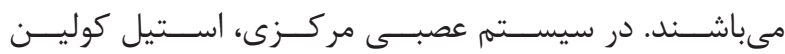

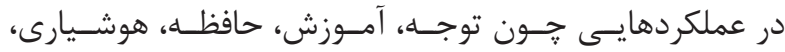

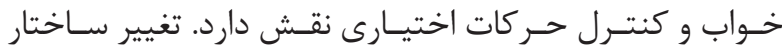

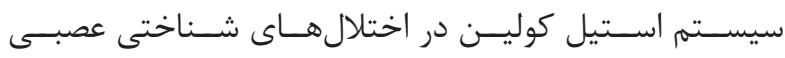

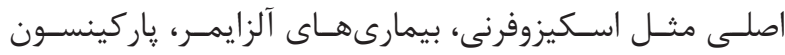

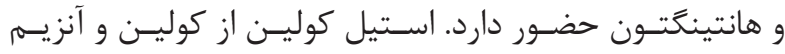

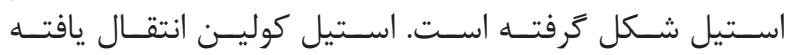

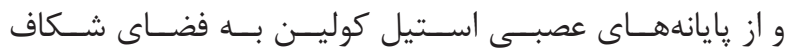

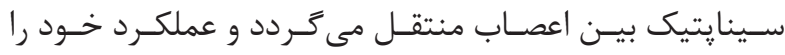

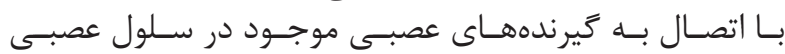

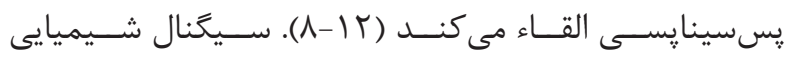

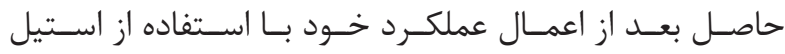

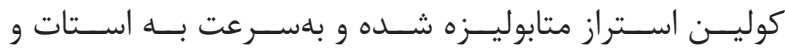

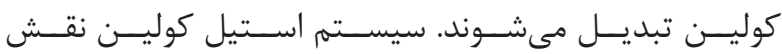

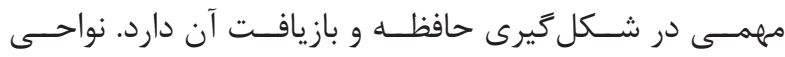

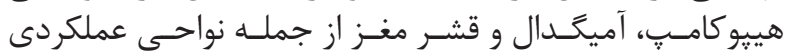

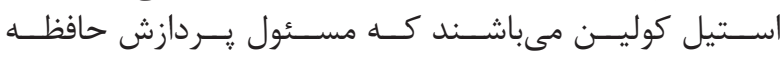

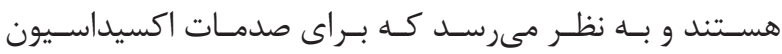

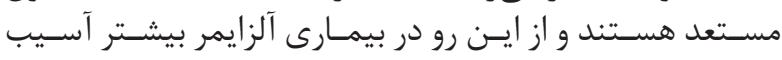

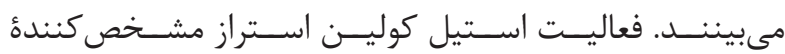

${ }^{15}$ Limbic areas

${ }^{16}$ Neurofibrillary tangles

${ }^{17}$ Signaling 


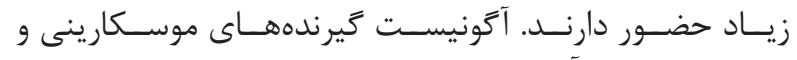

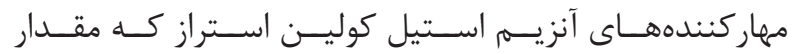

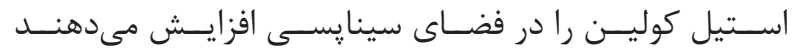

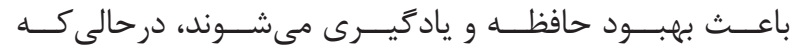

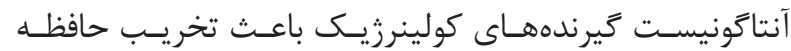

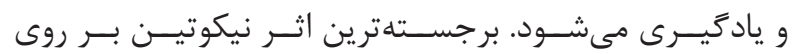

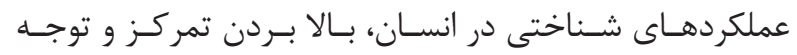

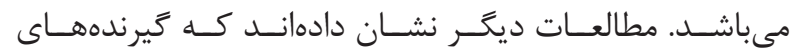

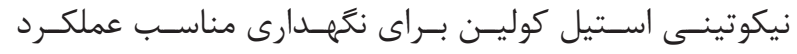

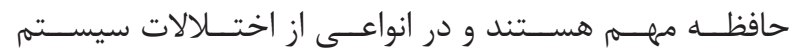

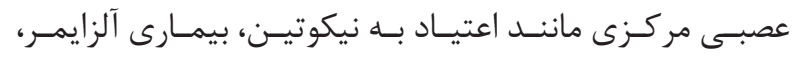

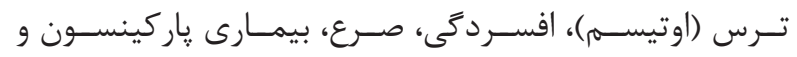

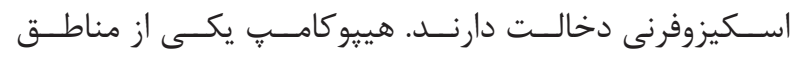

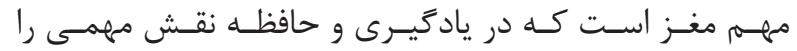

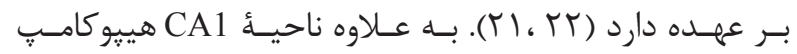

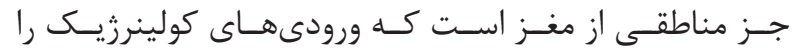

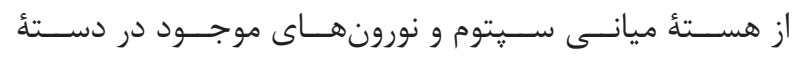

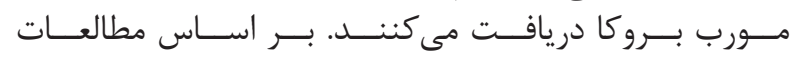

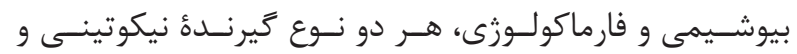

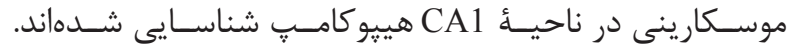

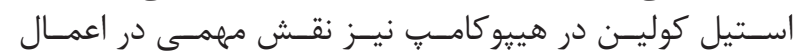

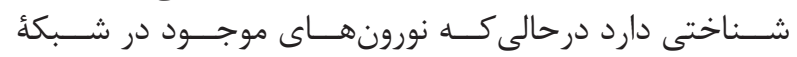

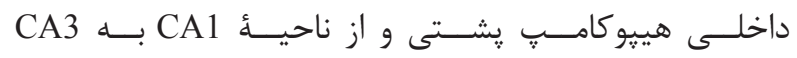

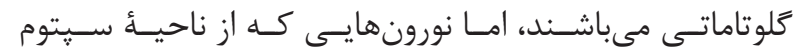

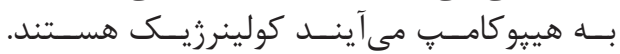

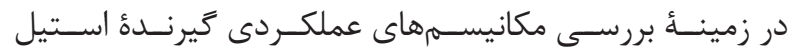

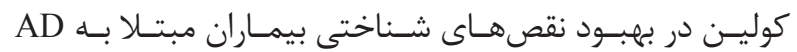

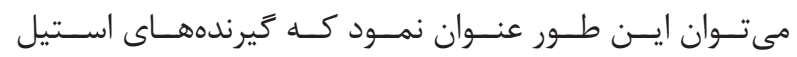

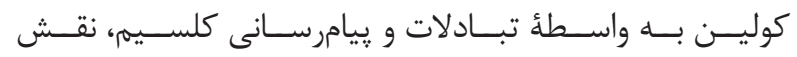

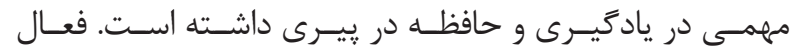

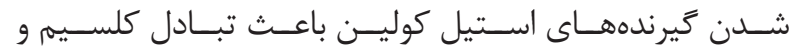

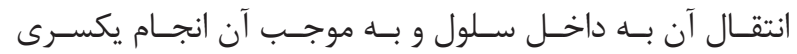

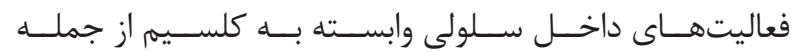

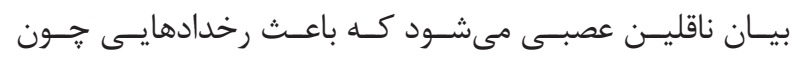

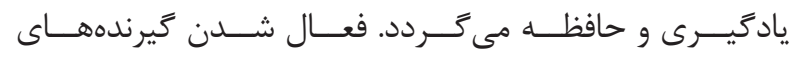

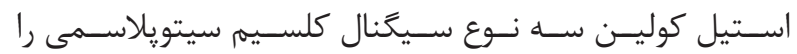

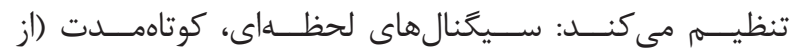

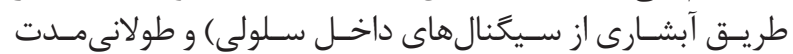

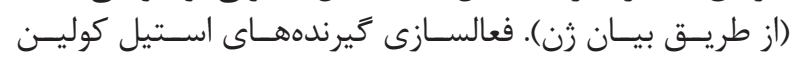

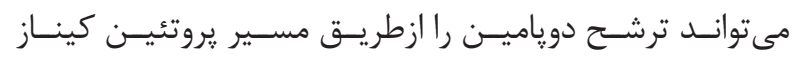
(PKC) C

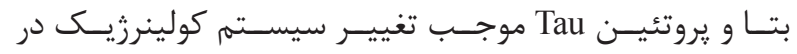

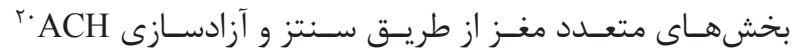

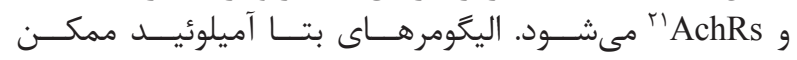

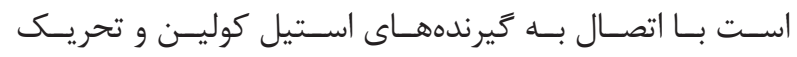

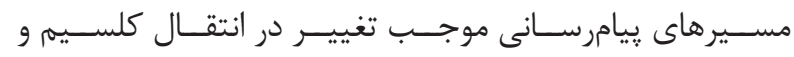

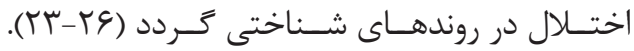

${ }^{18}$ Mild cognitive impairment

${ }^{19}$ Protein kinase $\mathrm{C}$
تجمعـات اينوزيتــول مىباشــد (IV- I I ).

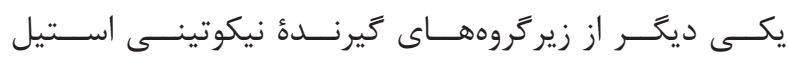

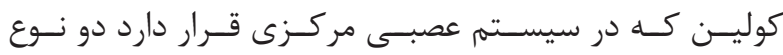

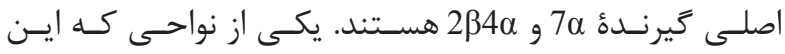

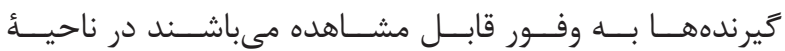

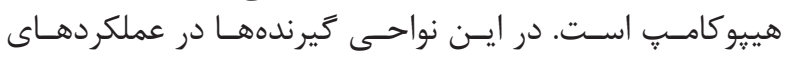

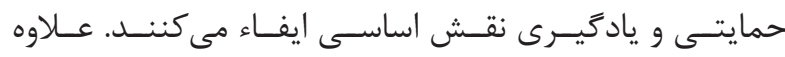

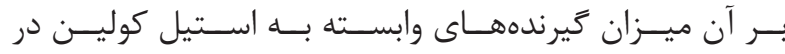

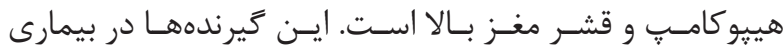

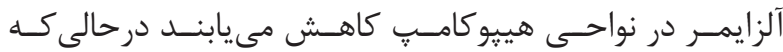

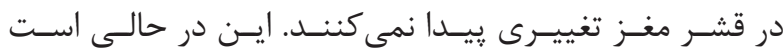

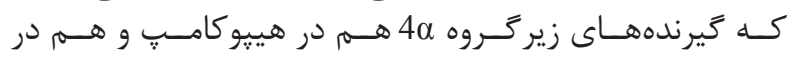

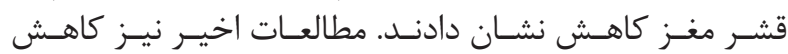

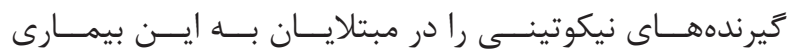

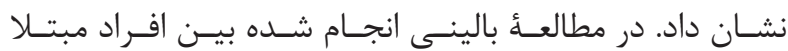

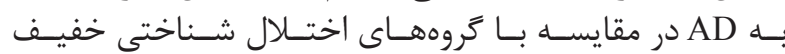

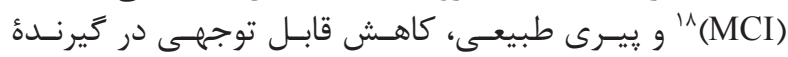

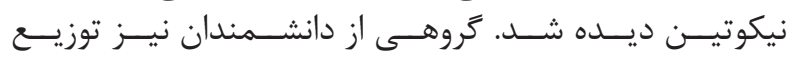

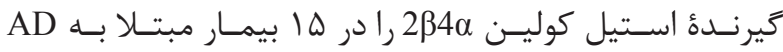

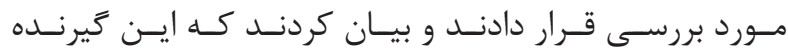

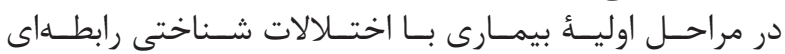

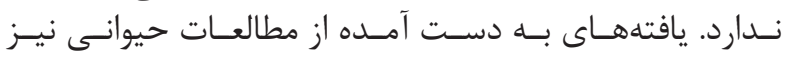

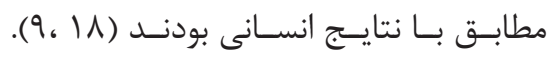

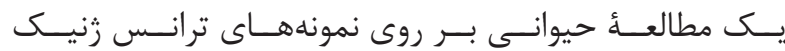

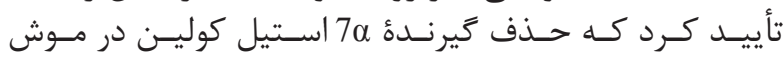

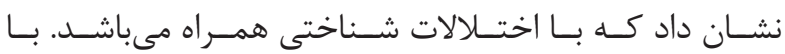

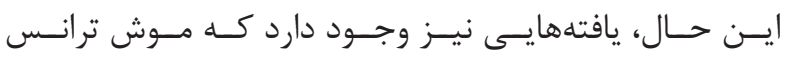

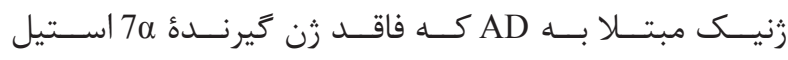

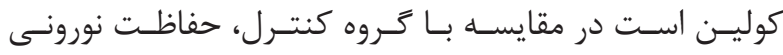

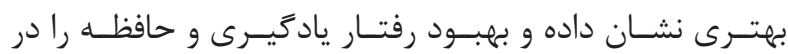

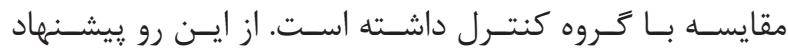

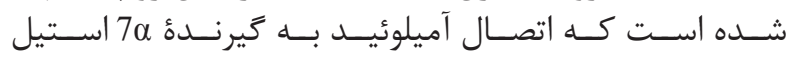

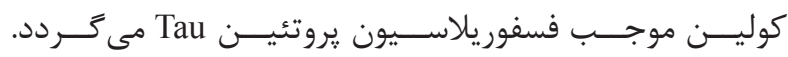

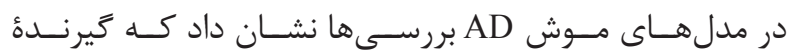

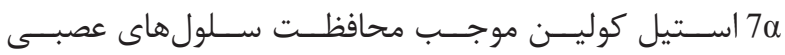

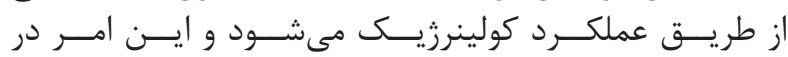

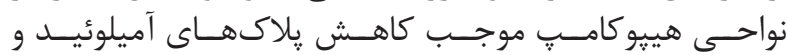

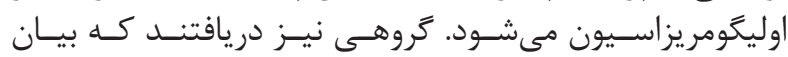

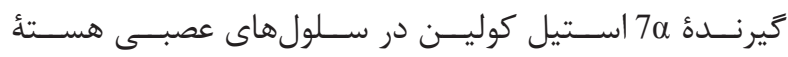

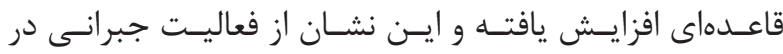

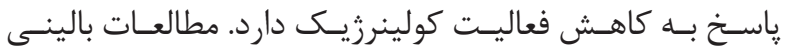

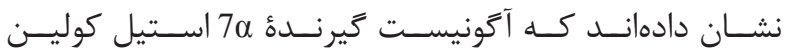

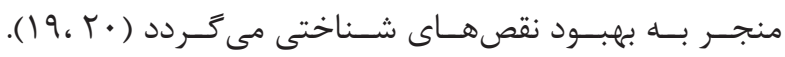

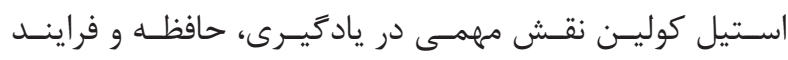

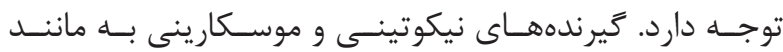

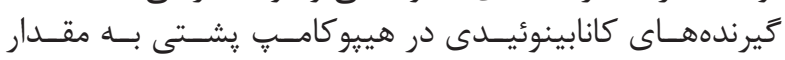

${ }^{20}$ Acetylcholine

${ }^{21}$ Acetylcholine receptor 


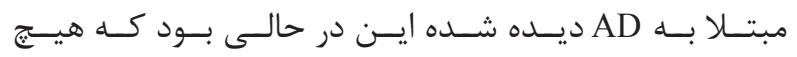

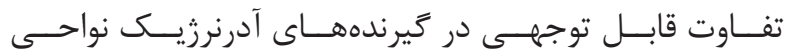

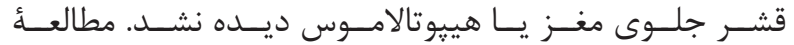

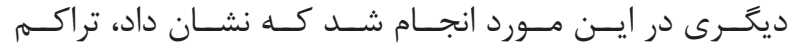

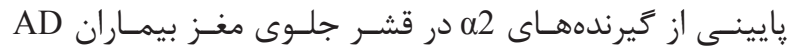

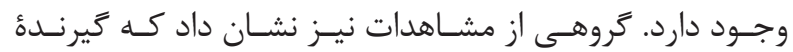

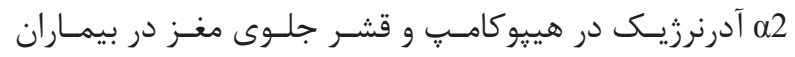

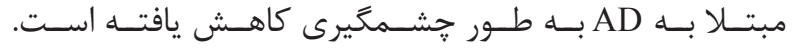

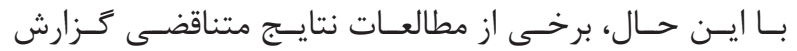

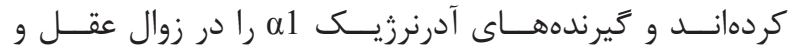

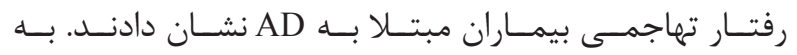

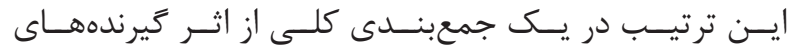

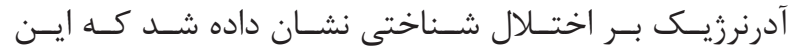

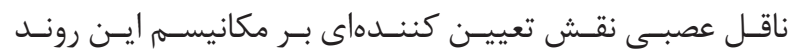

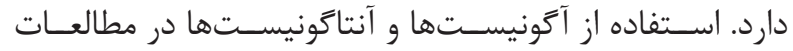

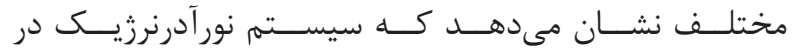

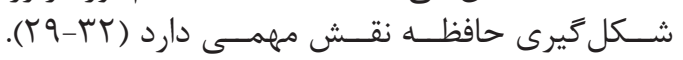

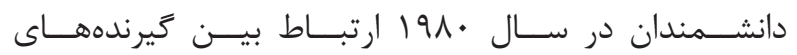

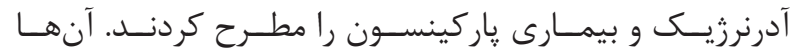

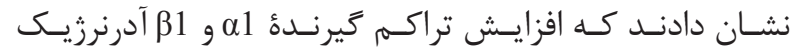

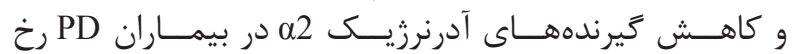

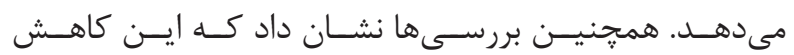

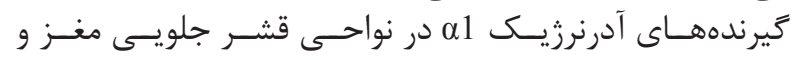

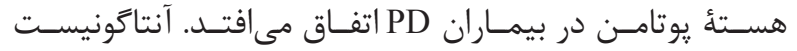

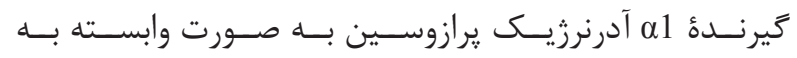

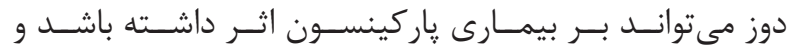

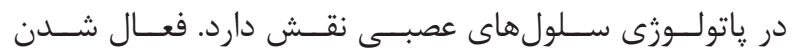

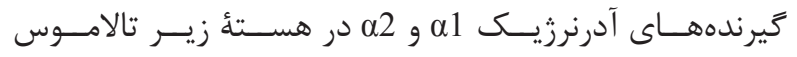

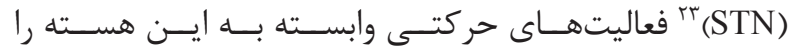

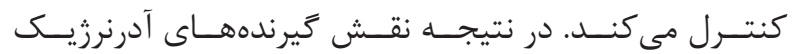

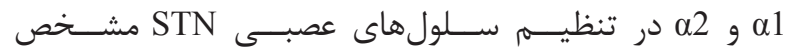

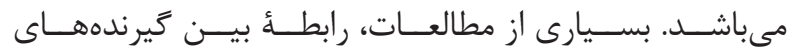

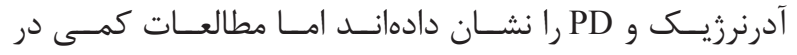

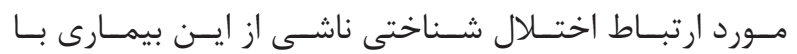

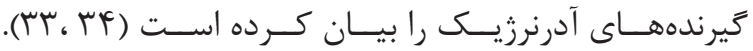

\section{r- گ گيرندهاى سروتونين}

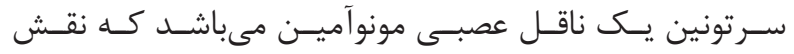

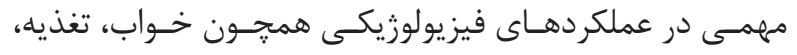

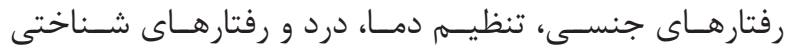

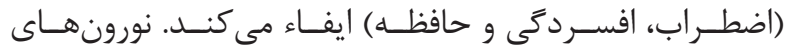

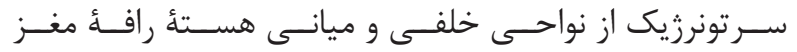

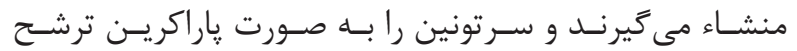

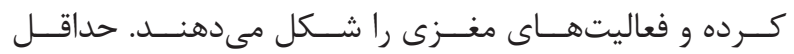

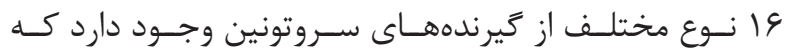

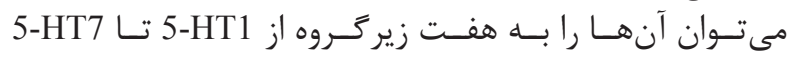

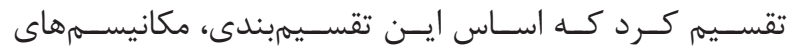

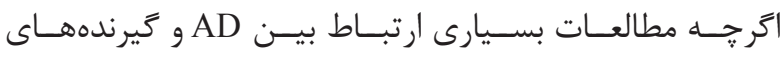

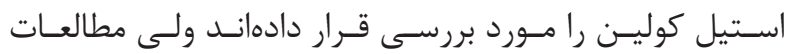

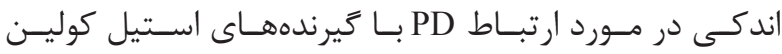

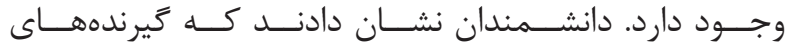

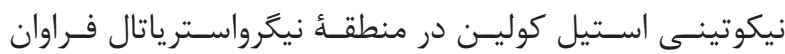

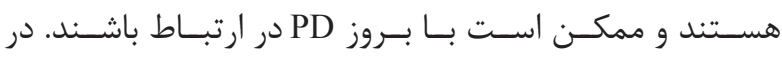

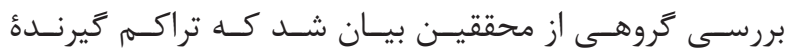
اســــا a4b2

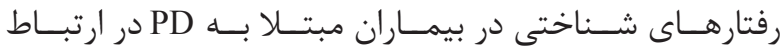

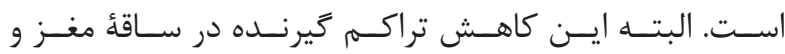

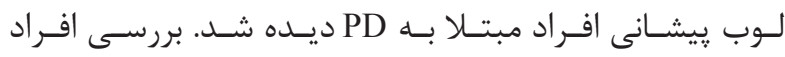

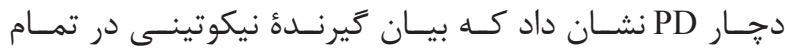

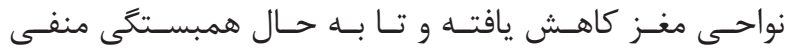

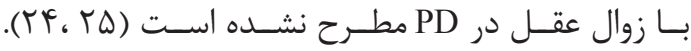

\section{ץ- Fيرندههاى آدرنرزيك}

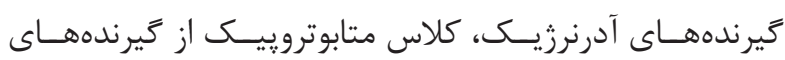
GPCRs

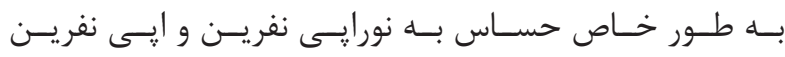

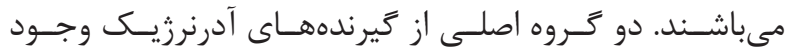

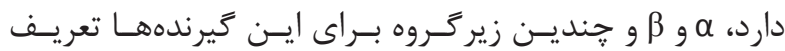

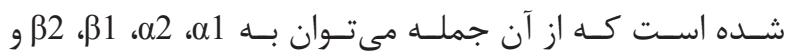

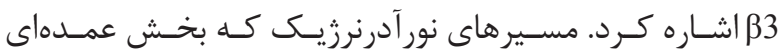

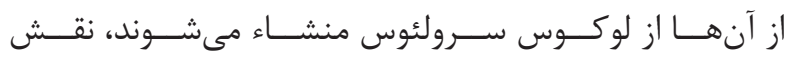

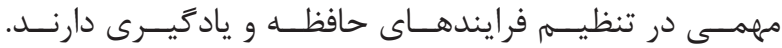

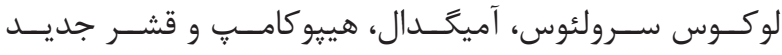

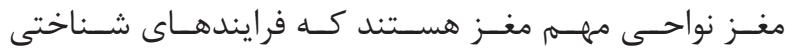

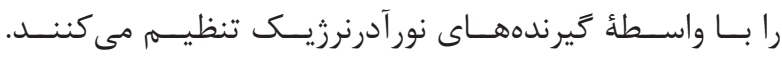

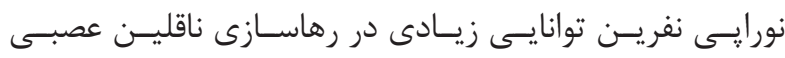

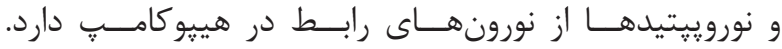

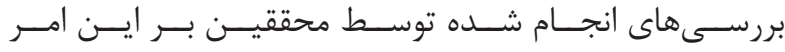

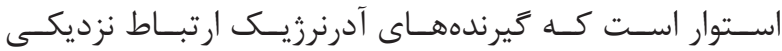

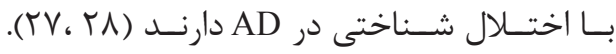

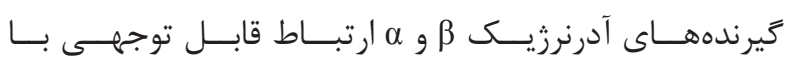

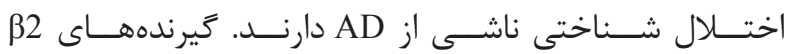

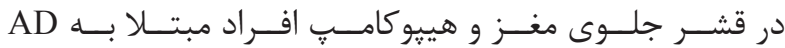

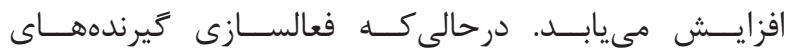

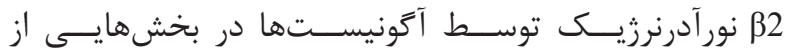

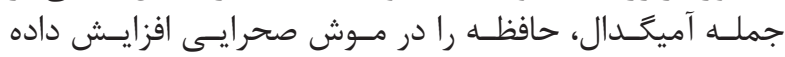

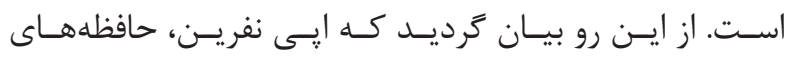

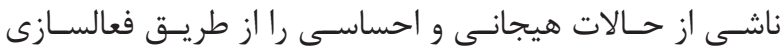

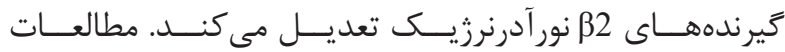

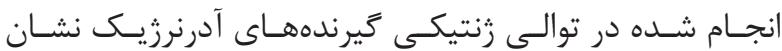

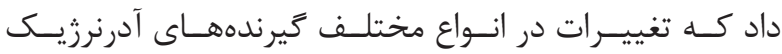

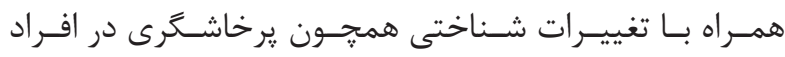

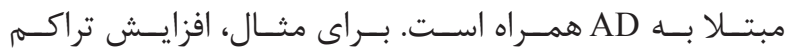

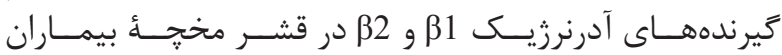

\footnotetext{
${ }^{22} \mathrm{G}$ protein-coupled receptors

${ }^{23}$ Subthalamic nucleus
} 


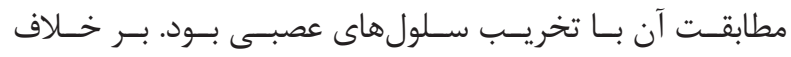

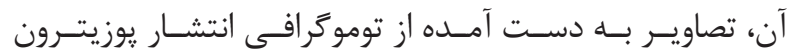

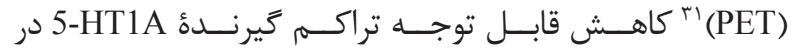

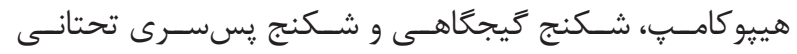

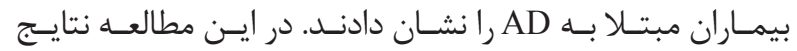

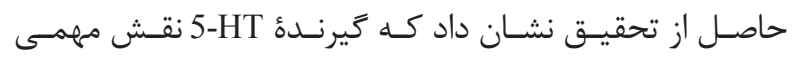

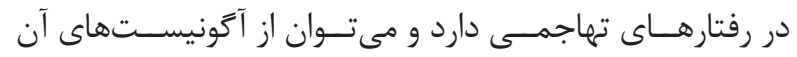

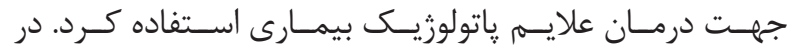

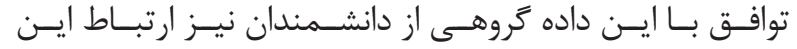

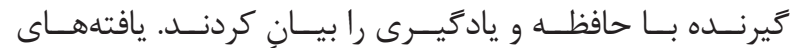

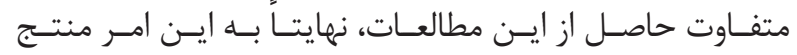

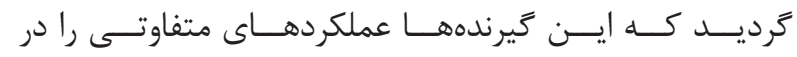

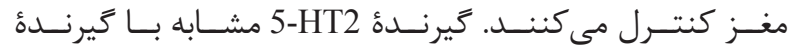

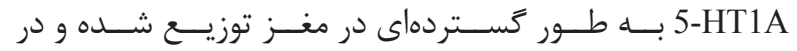

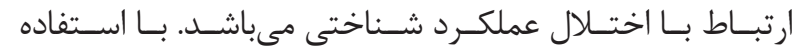

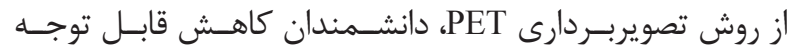

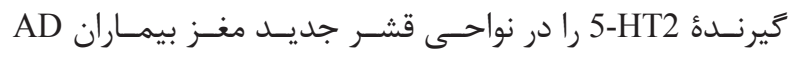

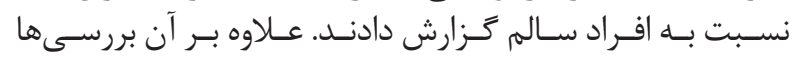

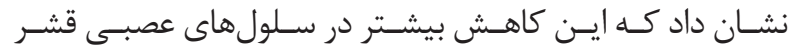

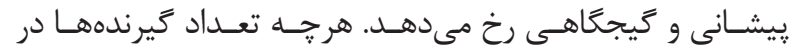

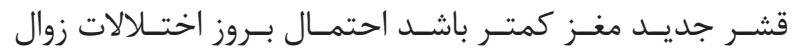

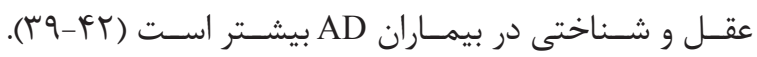

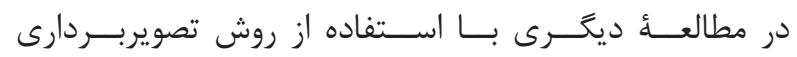

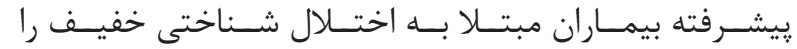

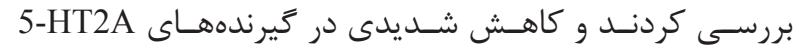

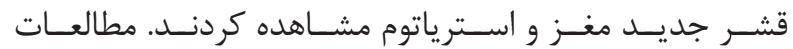

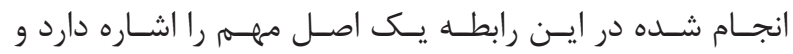

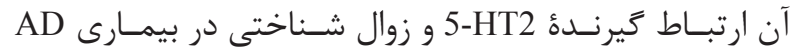

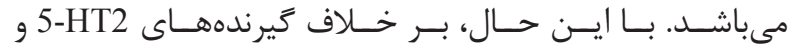

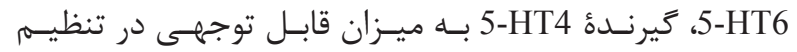

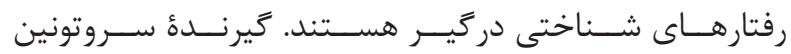

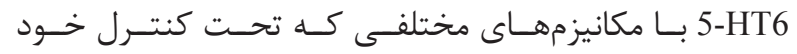

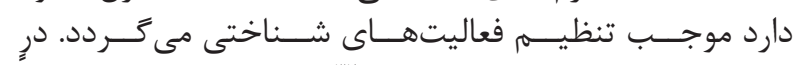

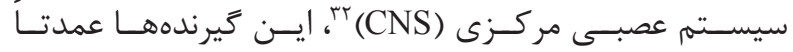

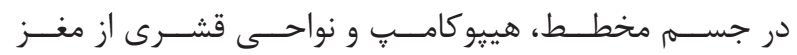

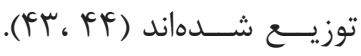

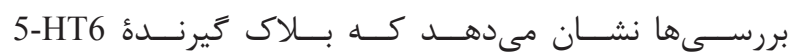

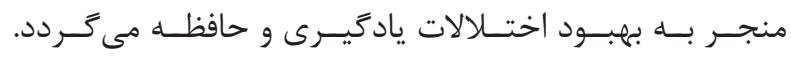

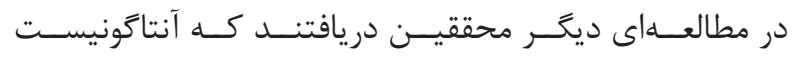

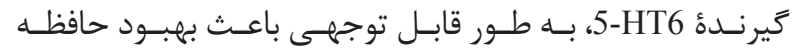

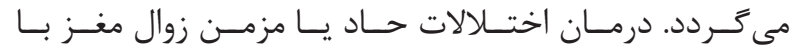

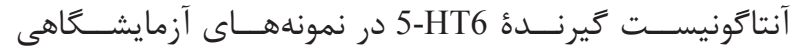

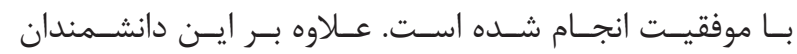

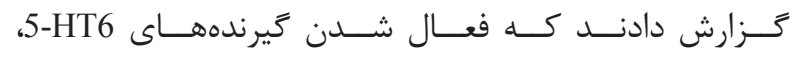

${ }^{24}$ Protein kinase A

${ }^{25}$ Phospholipase $\mathrm{C}$

${ }^{26}$ Neurodegenerative

${ }^{27}$ Dentate gyrus

${ }^{28}$ Mitogen-activated protein kinase

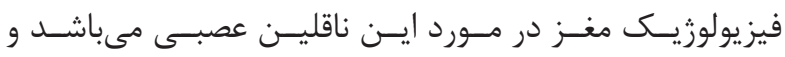

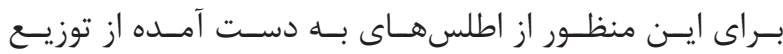

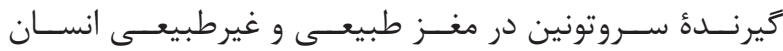

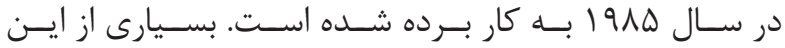

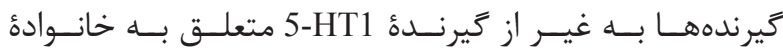

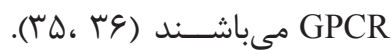

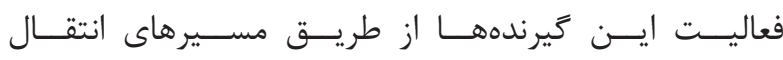

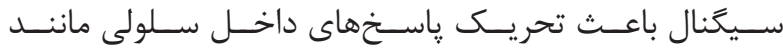

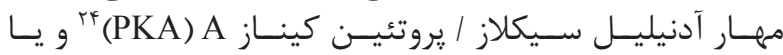

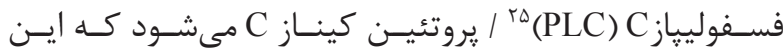

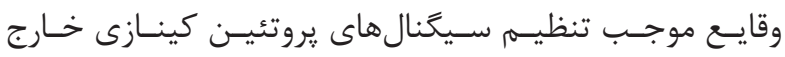

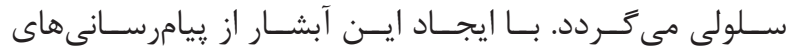

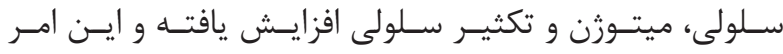

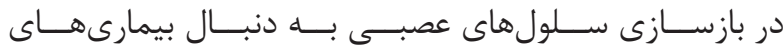

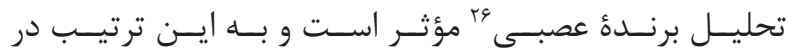

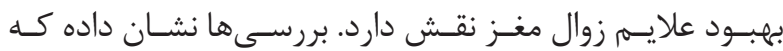

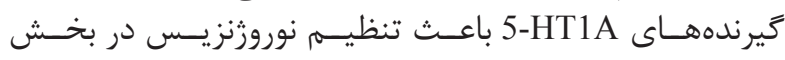

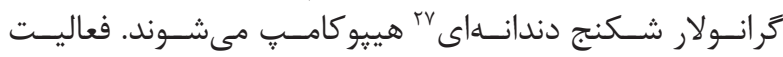

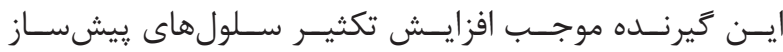

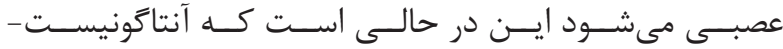

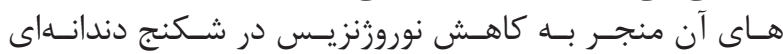

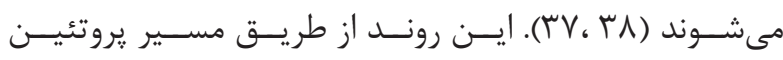

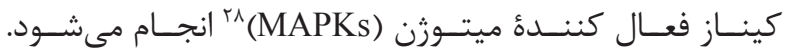

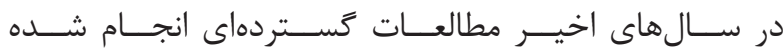

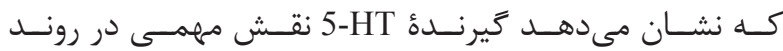

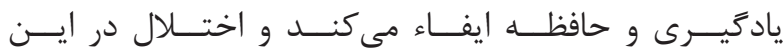

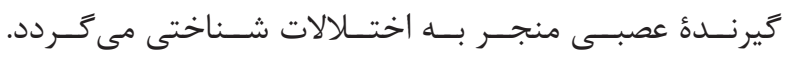

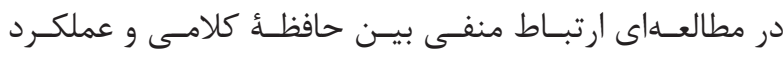

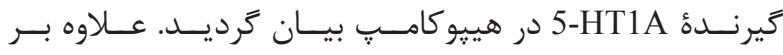

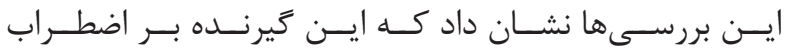

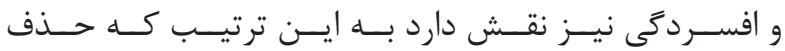

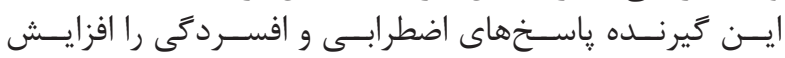

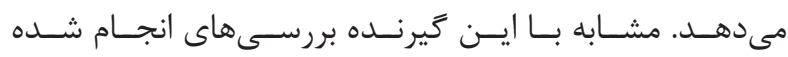

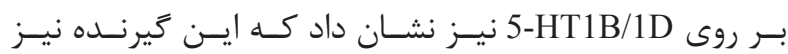

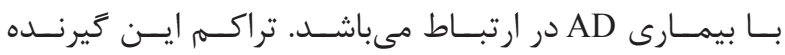

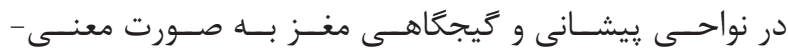

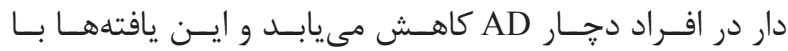

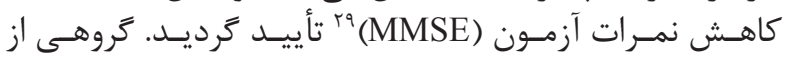

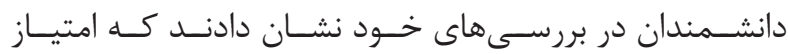

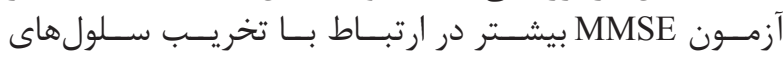

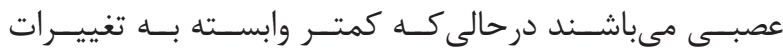

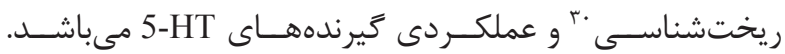

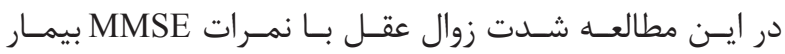

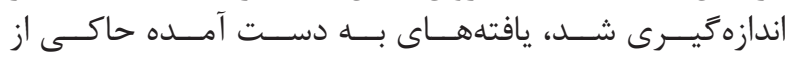

\footnotetext{
${ }^{29}$ Mini mental state examination

${ }^{30}$ Morphology

${ }^{31}$ Positron emission tomography

${ }^{32}$ Central nervous system
} 


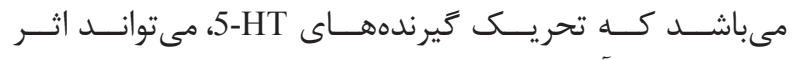

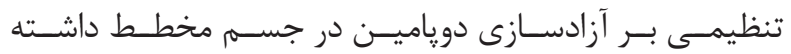

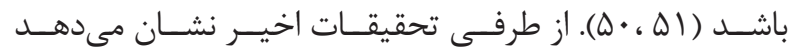

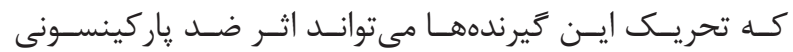

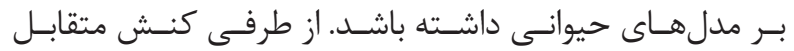

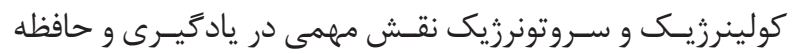

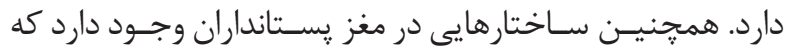

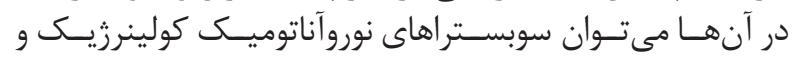

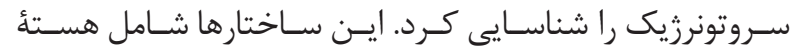

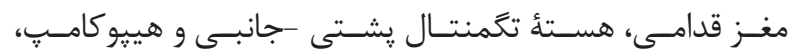

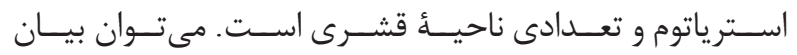

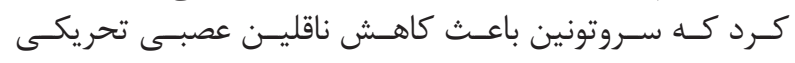

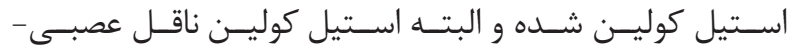

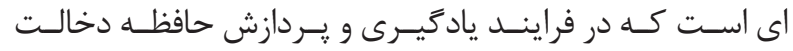

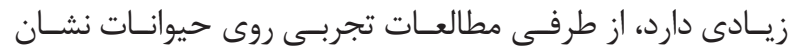

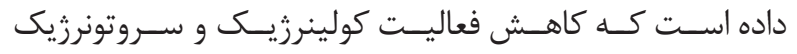

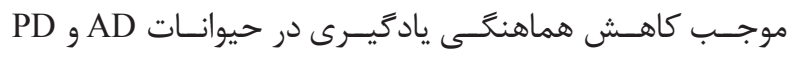

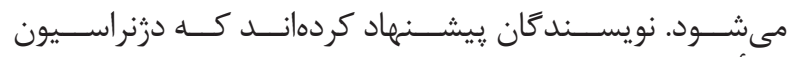

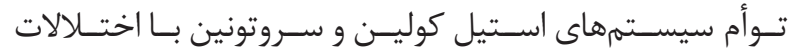

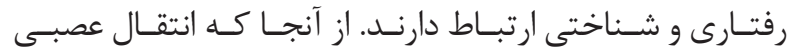

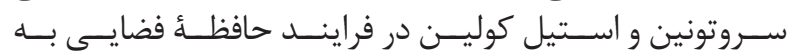

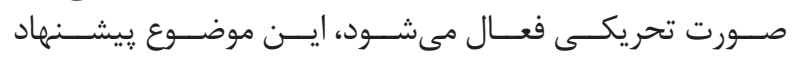

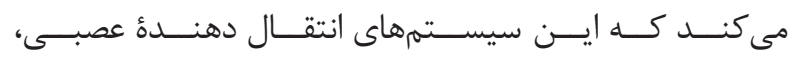

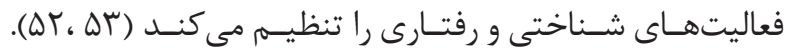

\section{F}

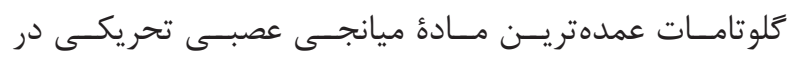

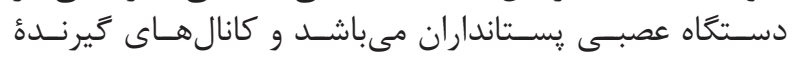

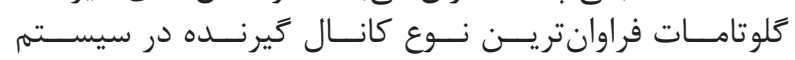

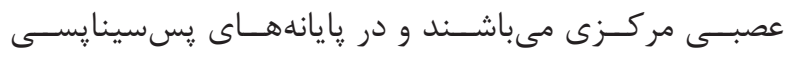

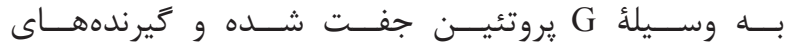

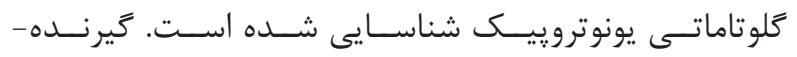

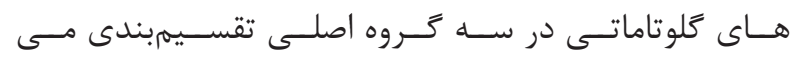

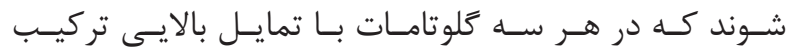

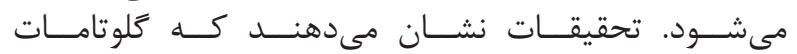

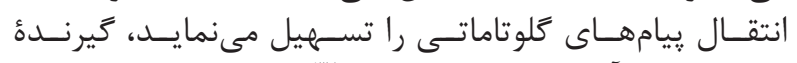

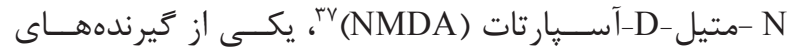

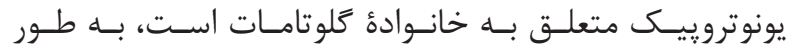

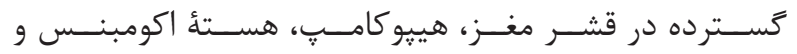

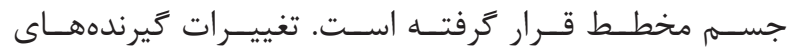
NMDA

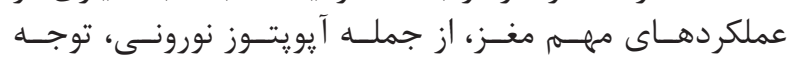

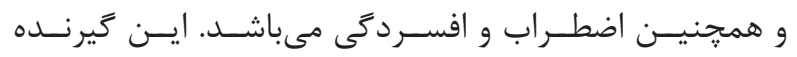

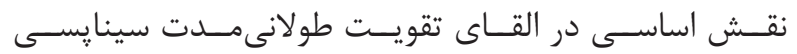

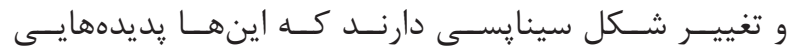

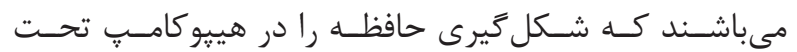

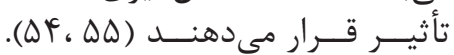

\footnotetext{
${ }^{33}$ Long-term potentiation

${ }^{34}$ Response element binding protein

${ }^{35}$ gamma-Aminobutyric acid
}

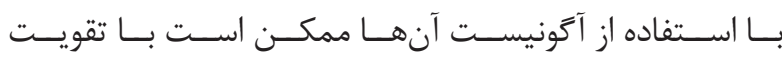

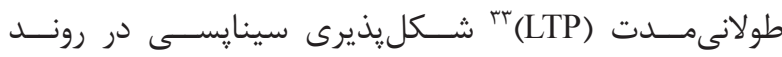

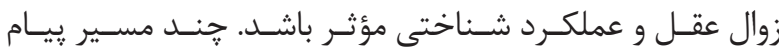

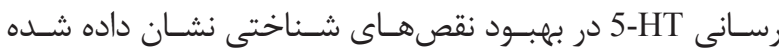

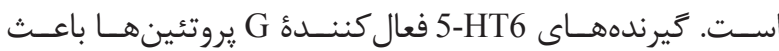

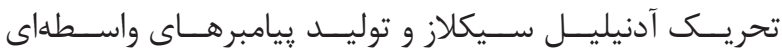

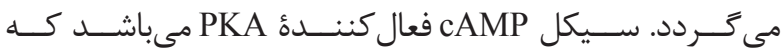

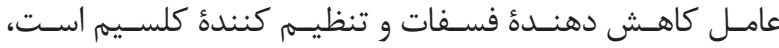

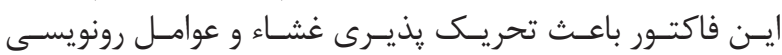

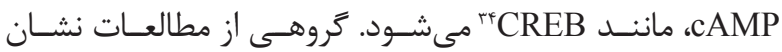

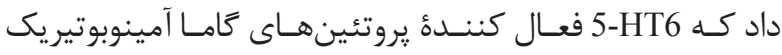

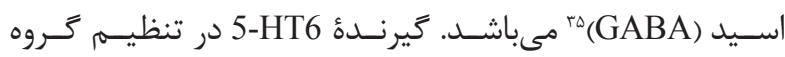
وسـيعى از ناقليـن عصبـى همجِ

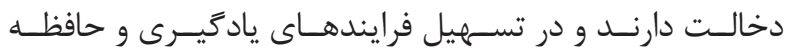

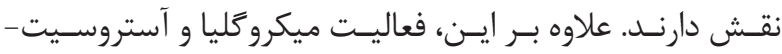

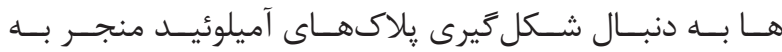

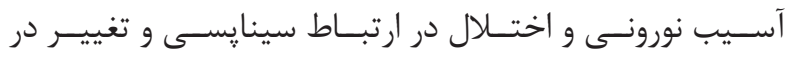

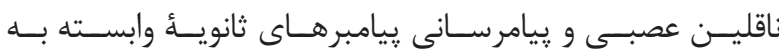

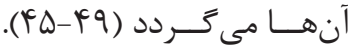

اختـلال PD بـا از دسـت دادن سـلول هاى عصبـى دويامينـى

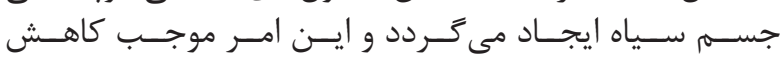

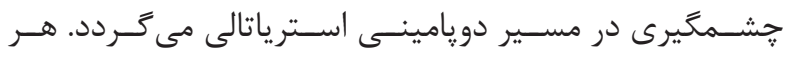

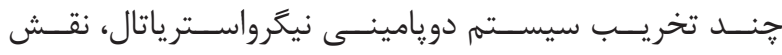

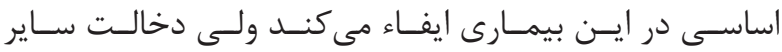

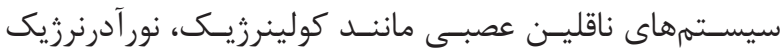

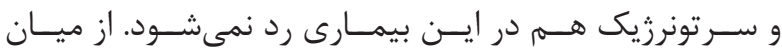

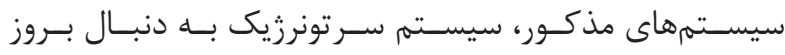

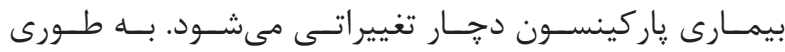

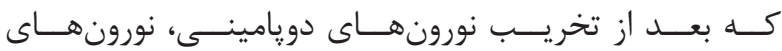

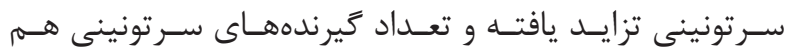

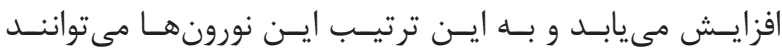

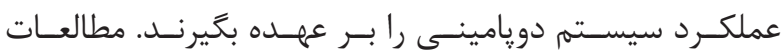

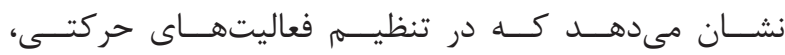

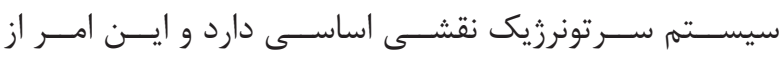

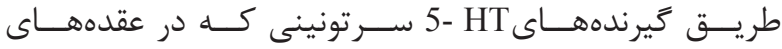

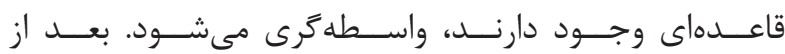

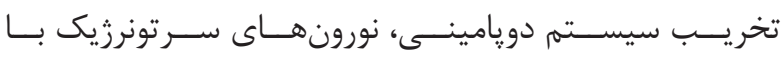

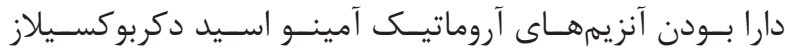
(AADC)

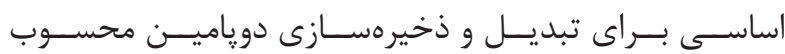

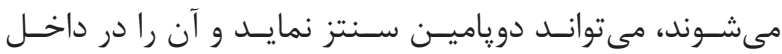

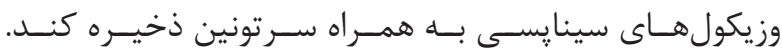

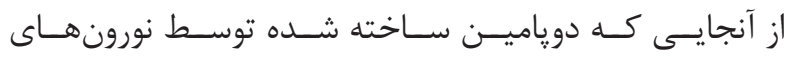

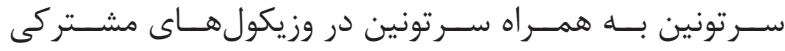

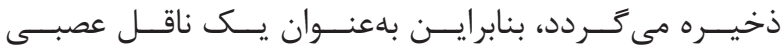

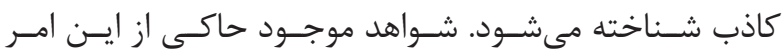

${ }^{36}$ Enzyme aromatic-L-amino-acid decarboxylase

${ }^{37} \mathrm{~N}$-methyl-D-aspartate 


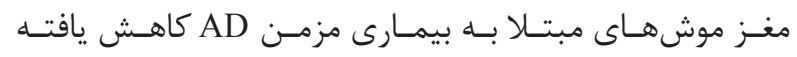

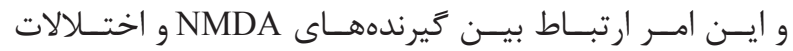

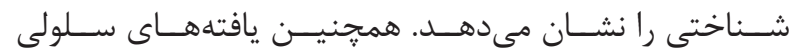

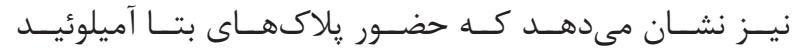

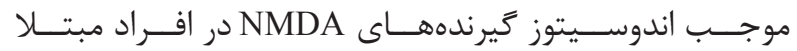

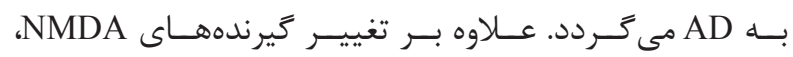

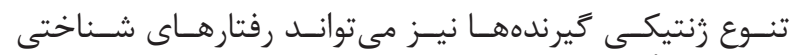

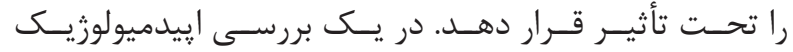

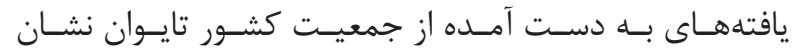

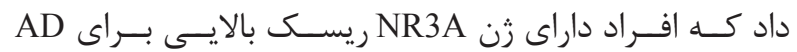

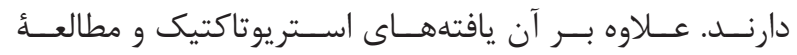

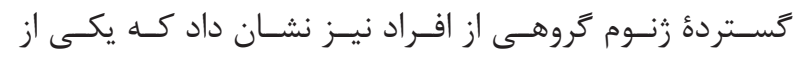

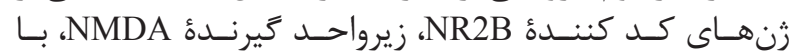

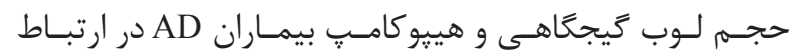

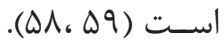

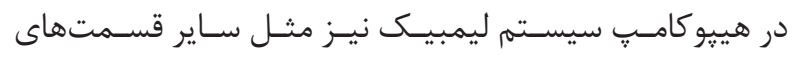

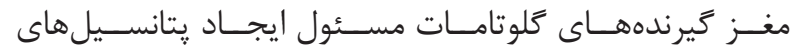

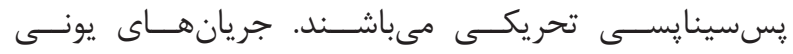

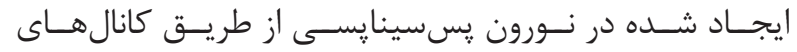

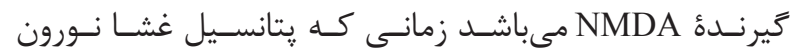

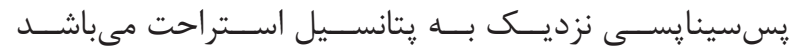

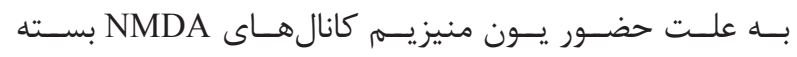

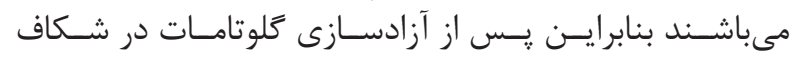

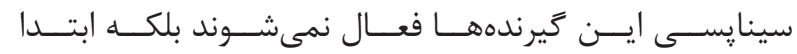

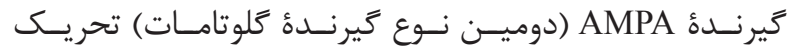

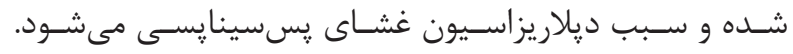

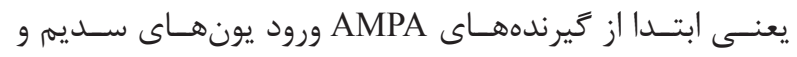

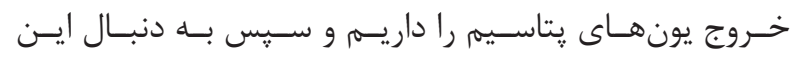

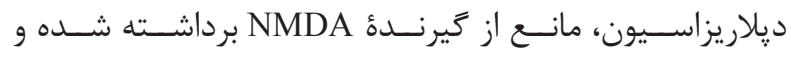

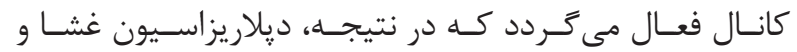

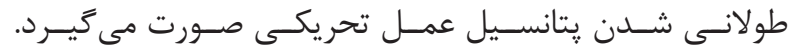

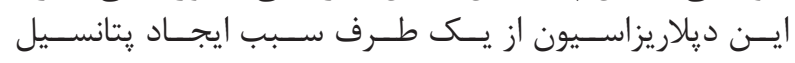

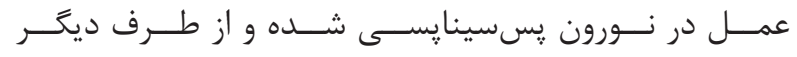

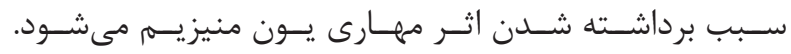

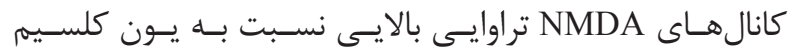

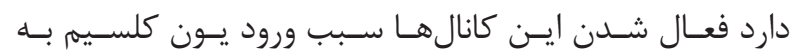

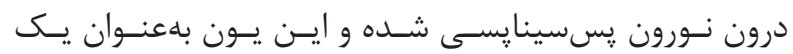

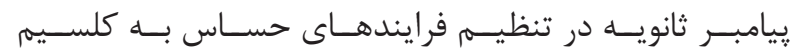

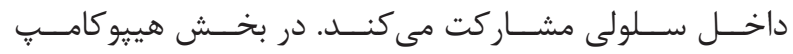

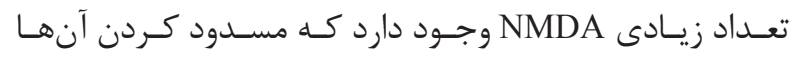

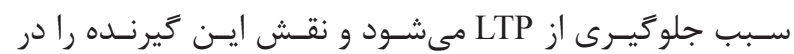

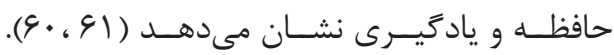

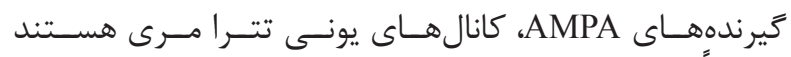

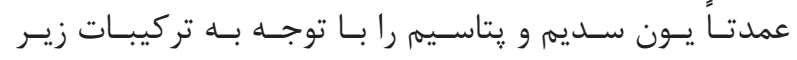

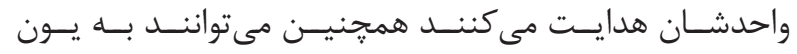

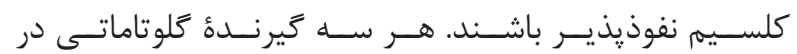

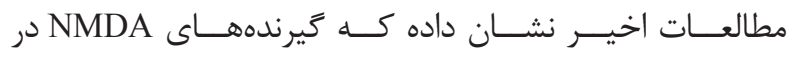

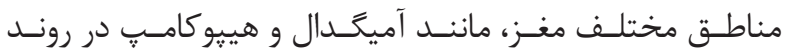

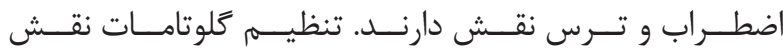

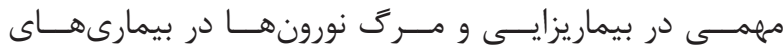

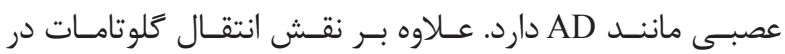

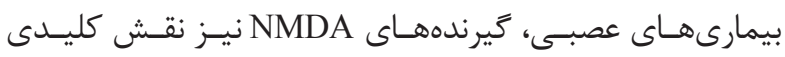

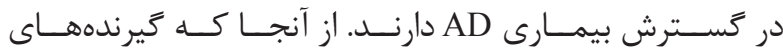

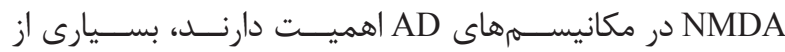

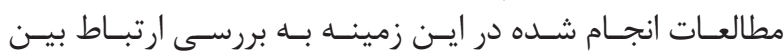

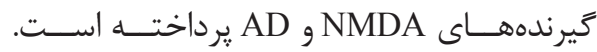

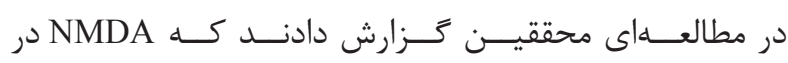

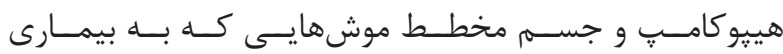

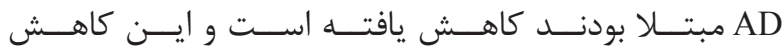

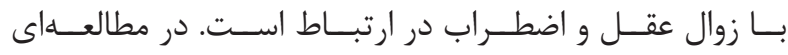

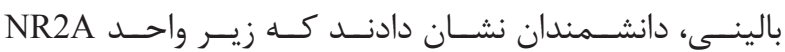

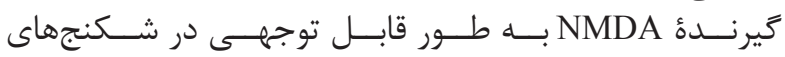

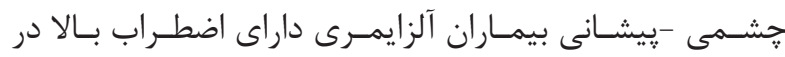

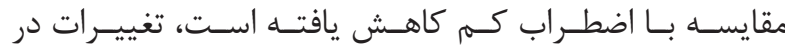

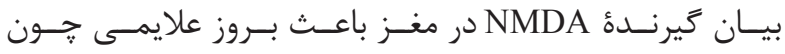

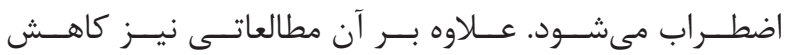

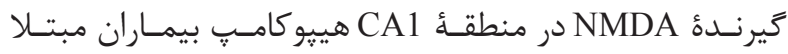

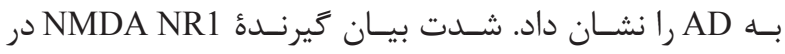

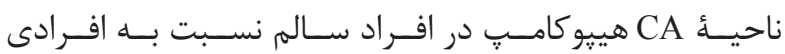

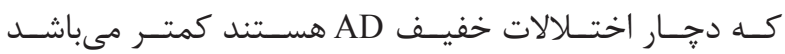

.$(\Delta \varphi, \Delta V)$

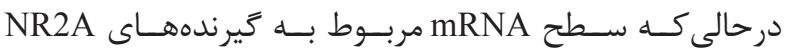

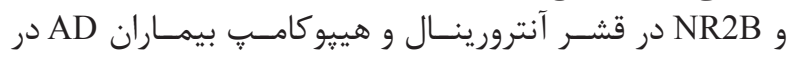

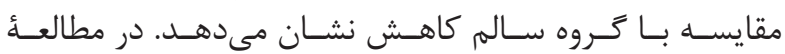

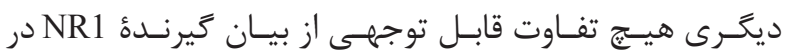

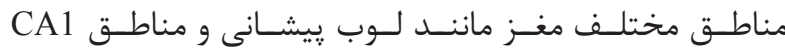

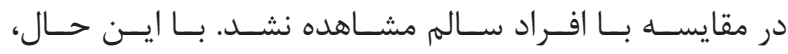

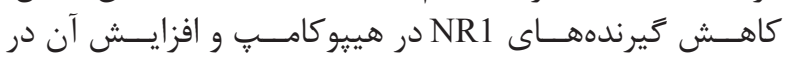

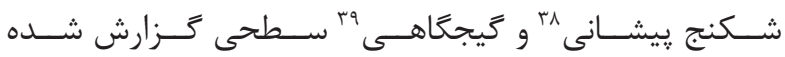

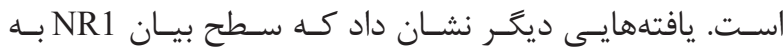

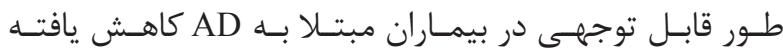

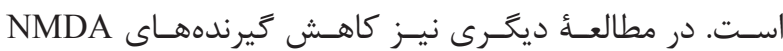

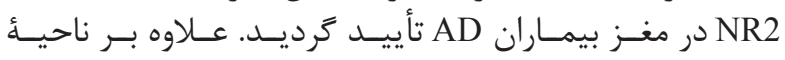

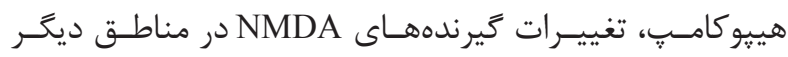

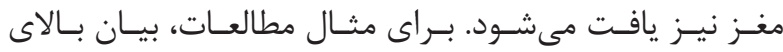

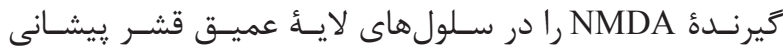

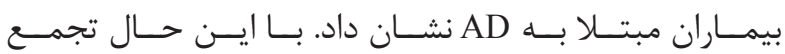

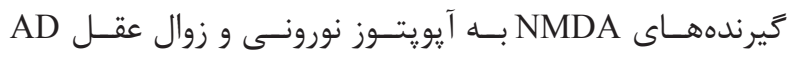

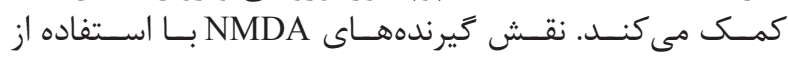

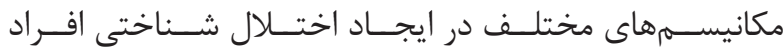

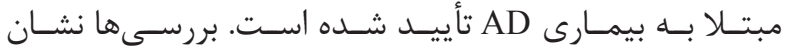

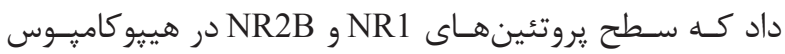




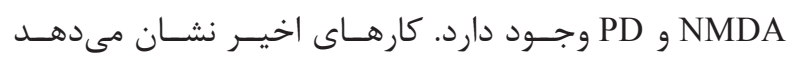

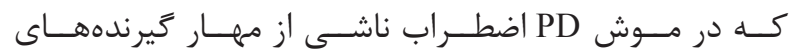

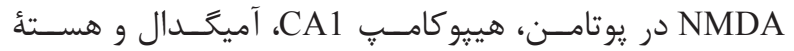

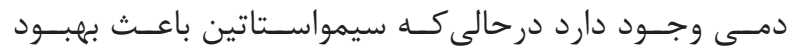

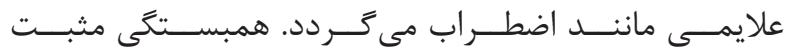

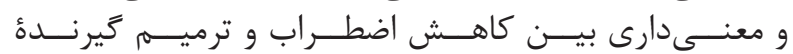

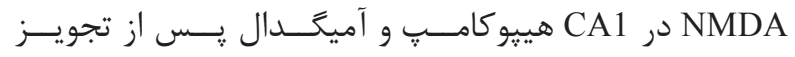

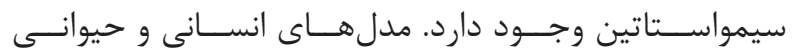

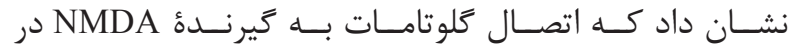

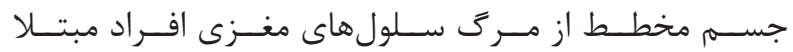

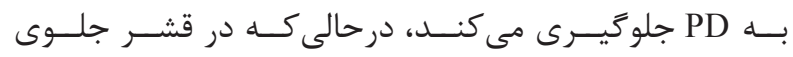

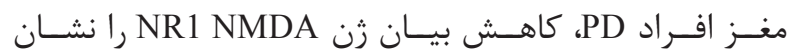

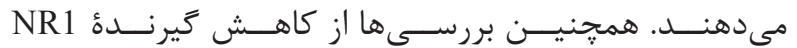

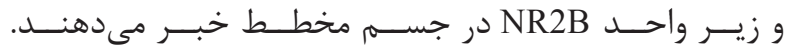

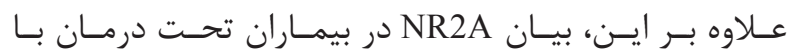

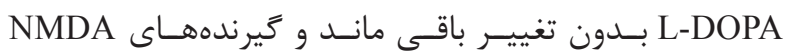

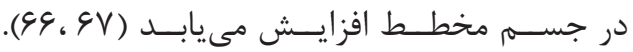

\section{ه- كير ندهاى دويامين}

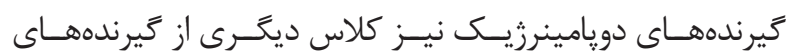

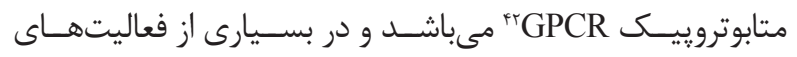

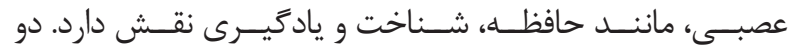

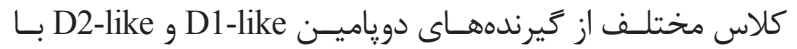

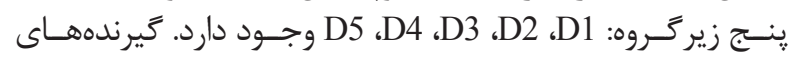

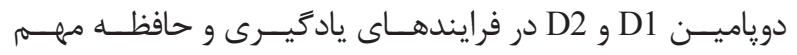

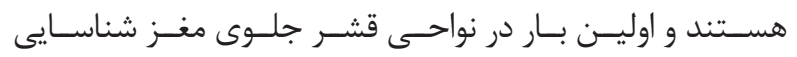

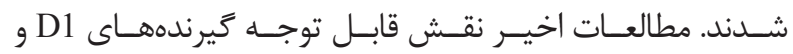

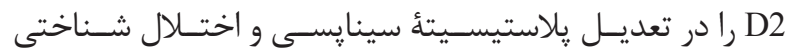

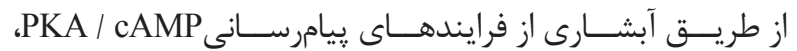

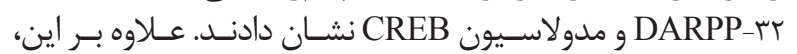

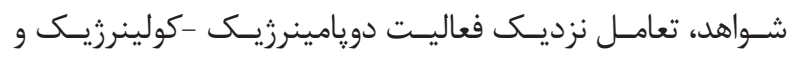

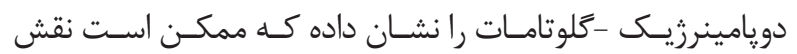

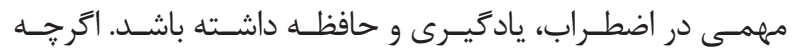

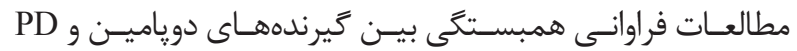

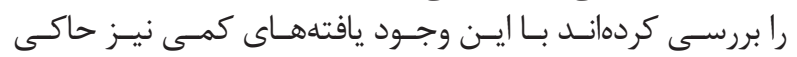

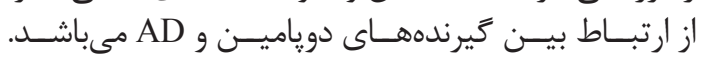

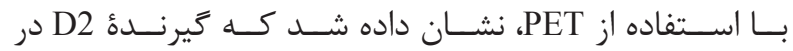

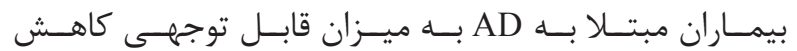

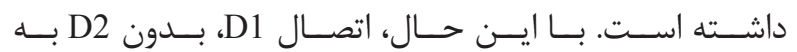

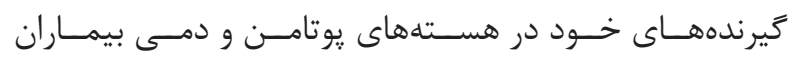

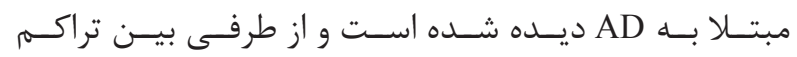

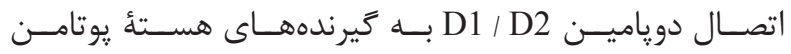

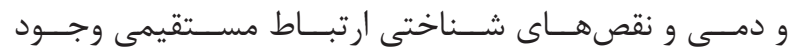

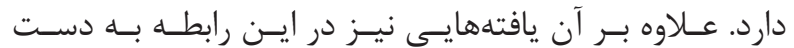

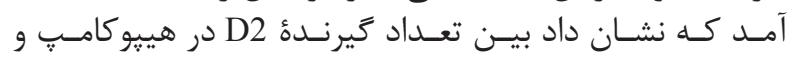

${ }^{40}$ Fear memory

${ }^{41}$ Oxidative stress

${ }^{42}$ G-protein-coupled

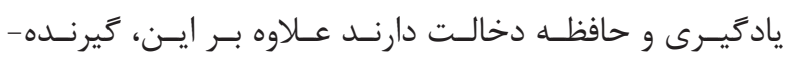

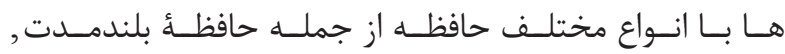

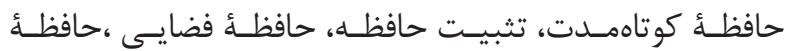

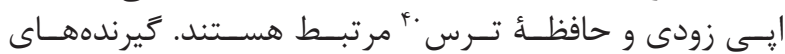

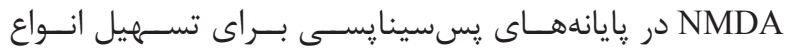

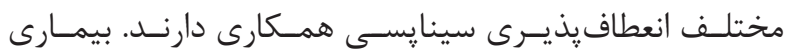

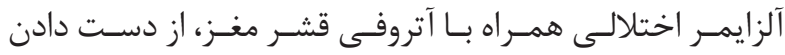

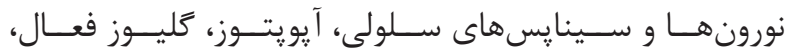

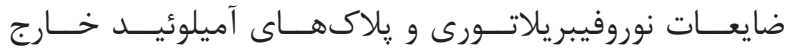

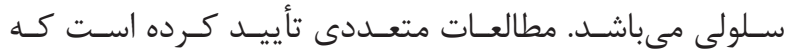

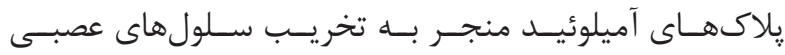

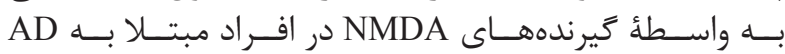

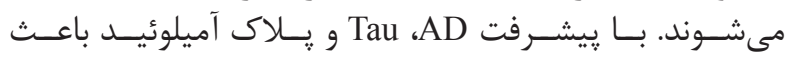

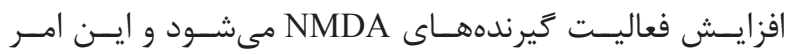

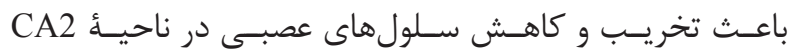

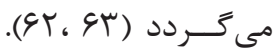

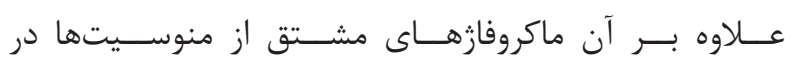

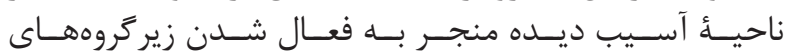

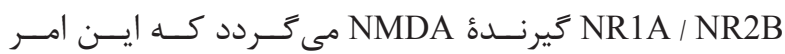

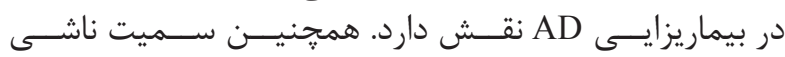

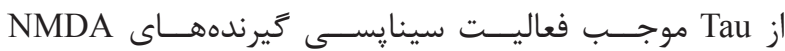

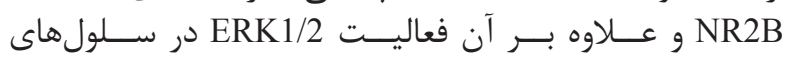

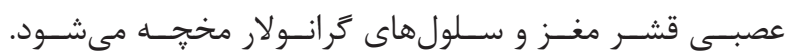

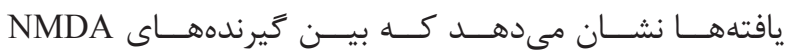

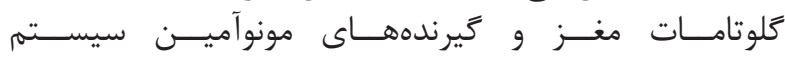

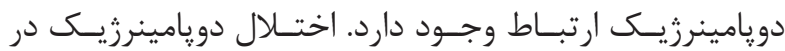

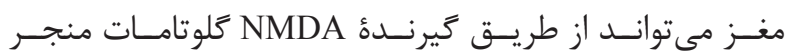

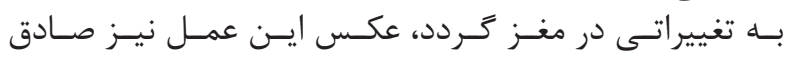

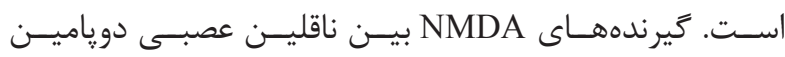

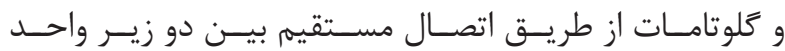

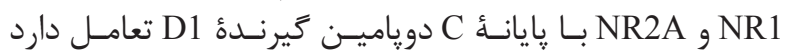

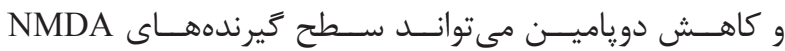

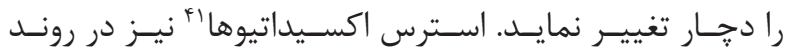

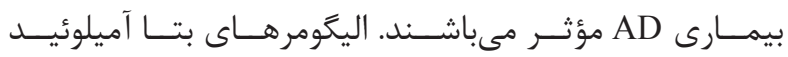

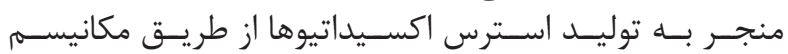

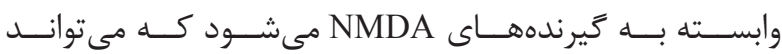

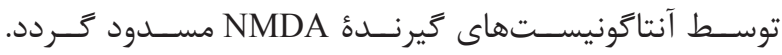

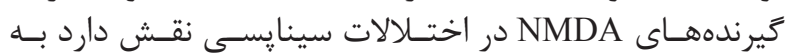

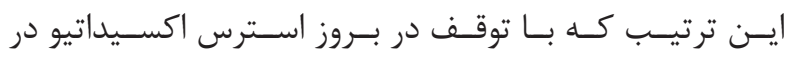

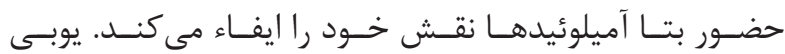

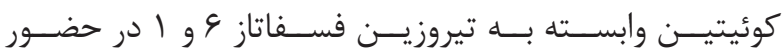

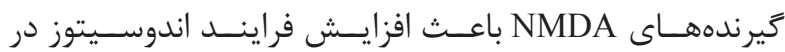

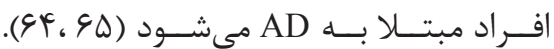

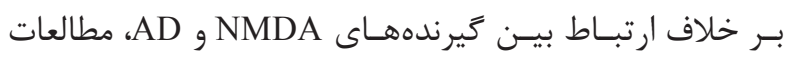

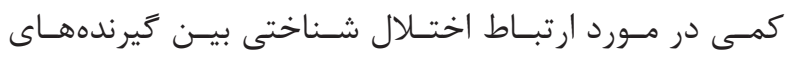




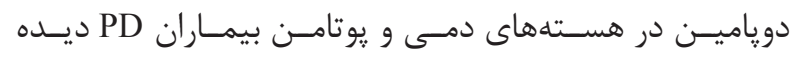

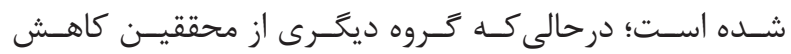

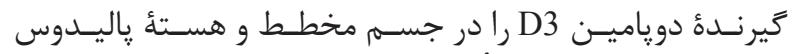

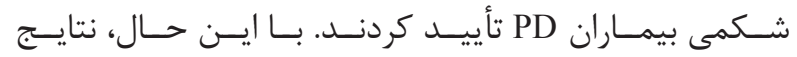

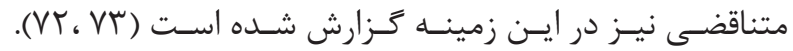

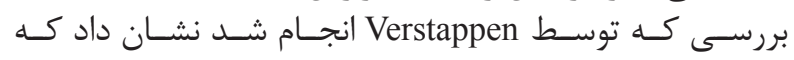

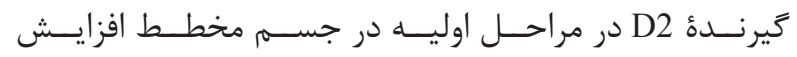

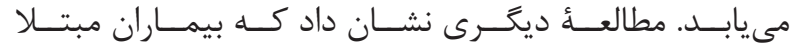

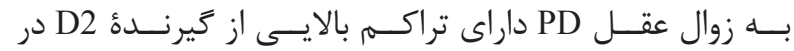

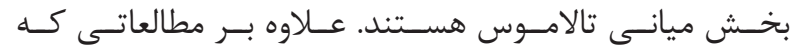

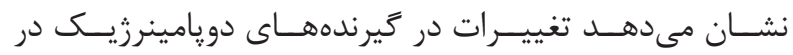

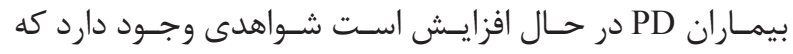

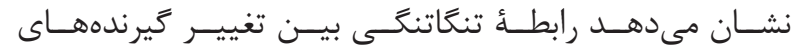

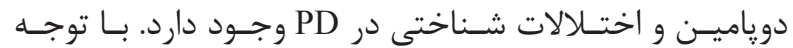

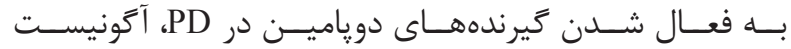

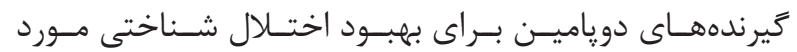

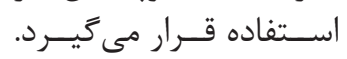

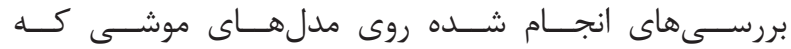

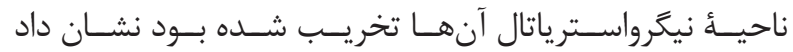

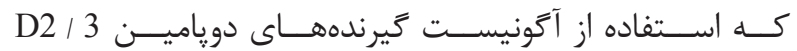

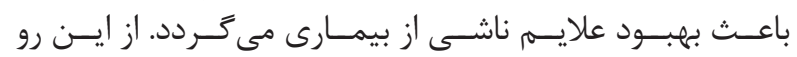

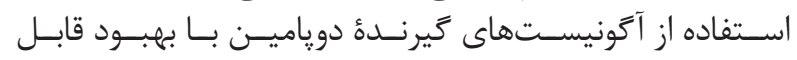

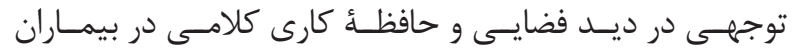

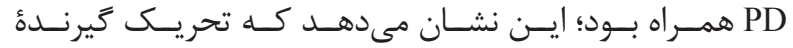

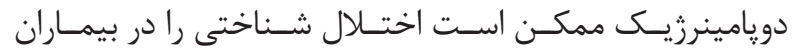

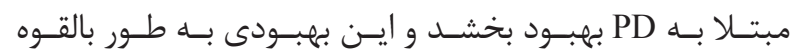

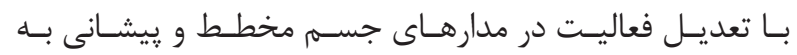

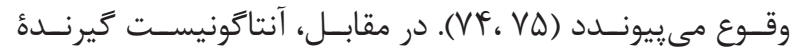

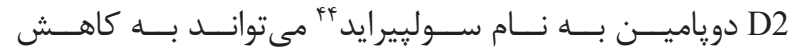

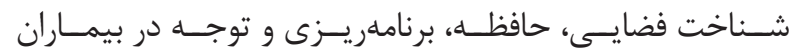

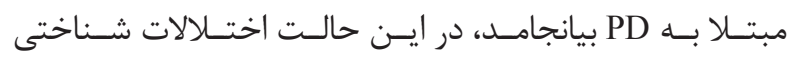

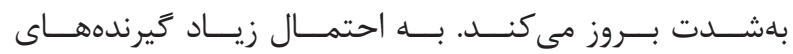

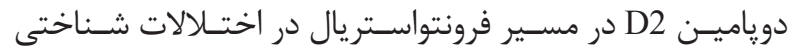

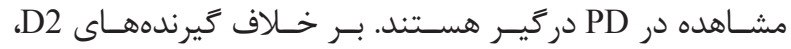

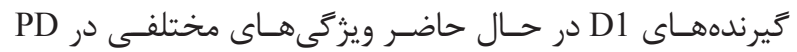

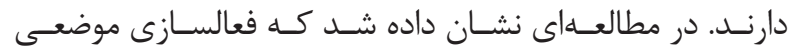

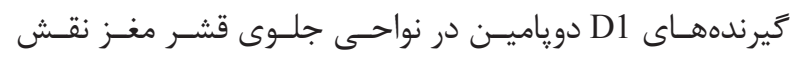

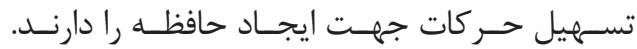

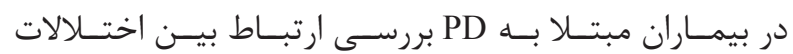

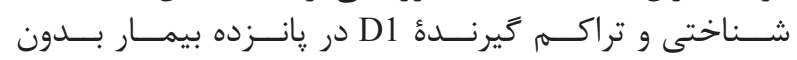

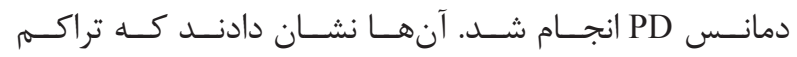

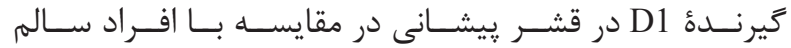

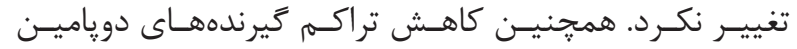

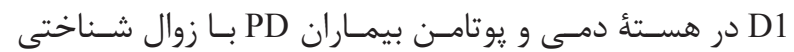

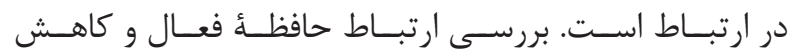

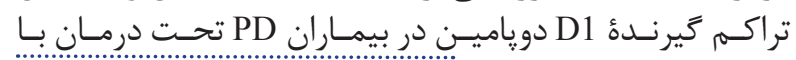
${ }^{43}$ Prefrontal cortex

${ }^{44}$ Sulpiride

${ }^{45}$ Pergolide

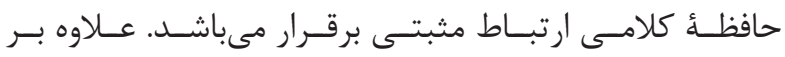

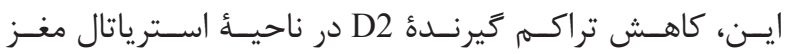

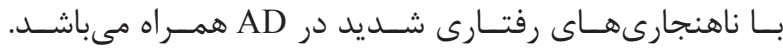

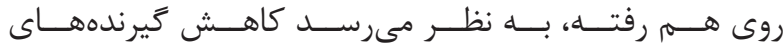

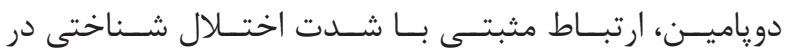

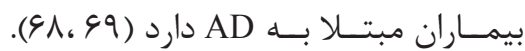

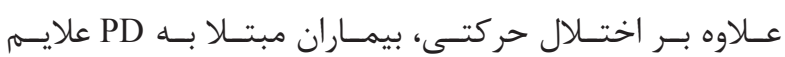

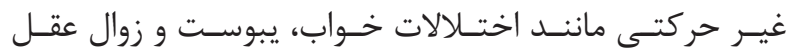

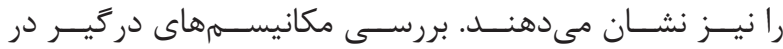

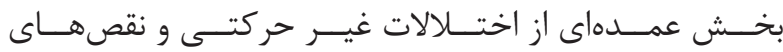

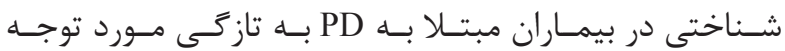

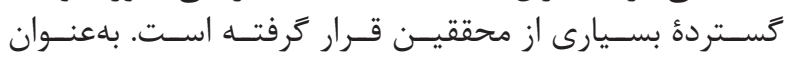

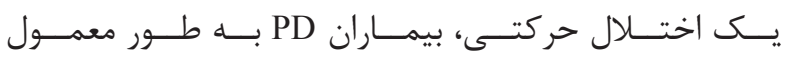

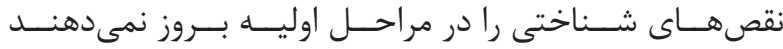

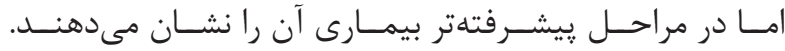

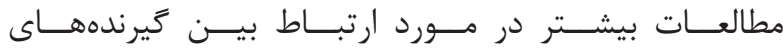

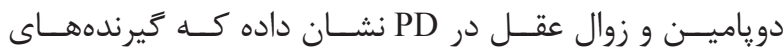

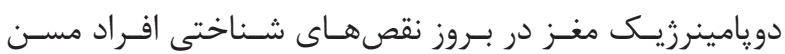

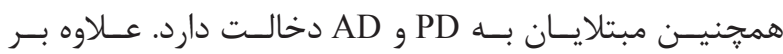

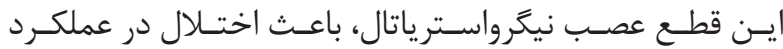

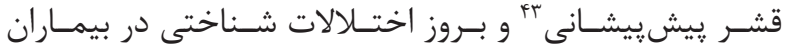

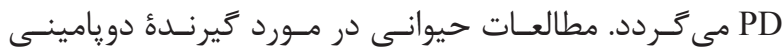

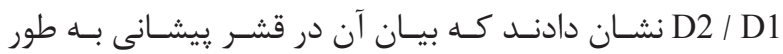

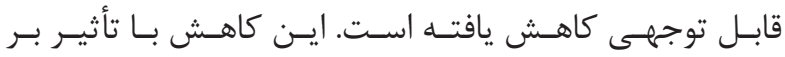

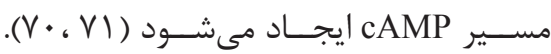

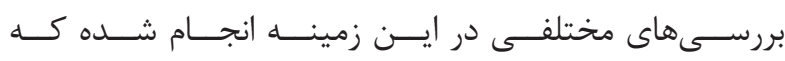

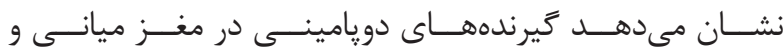

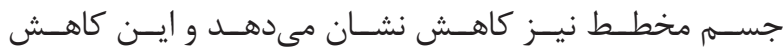

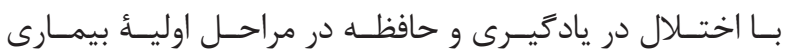

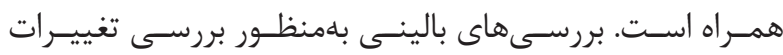

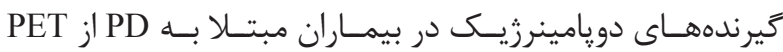

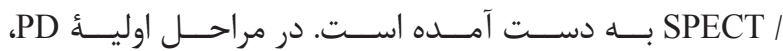

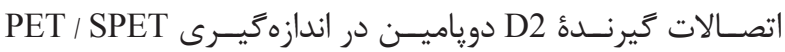

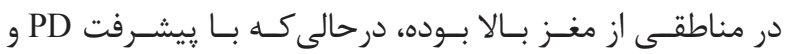

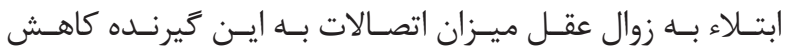

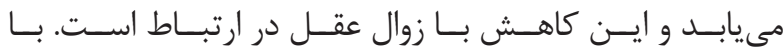

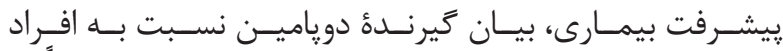

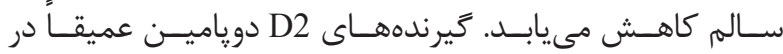

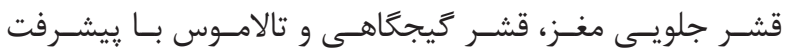

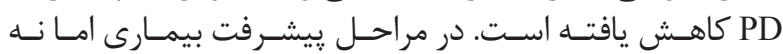

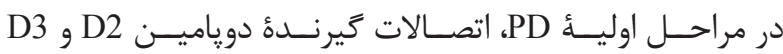

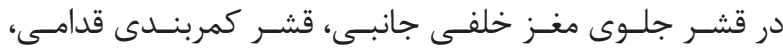

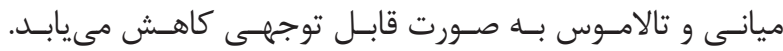

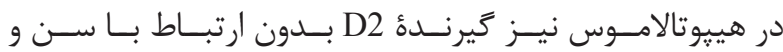

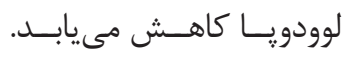

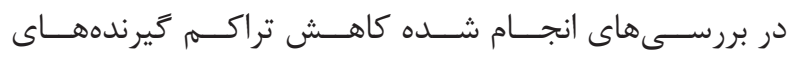




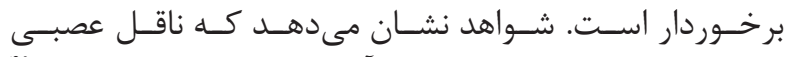

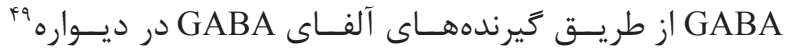

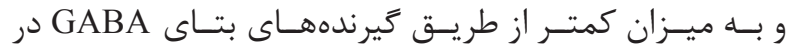

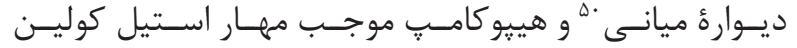

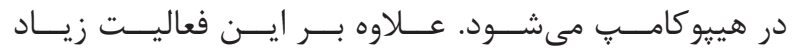

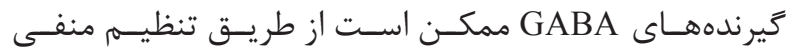

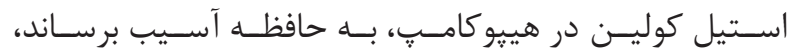

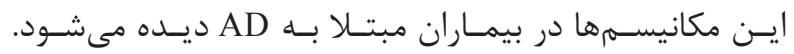

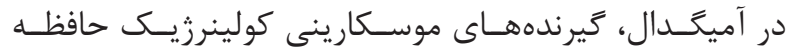

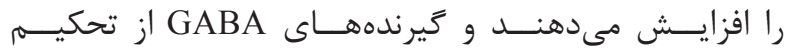

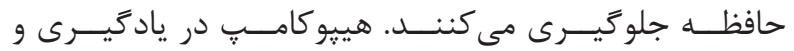

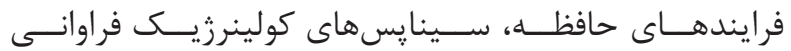

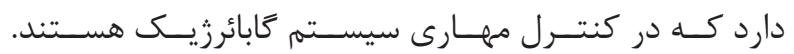

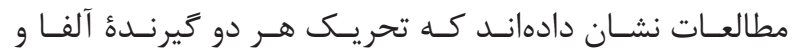

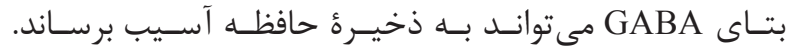

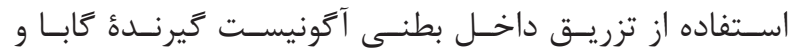

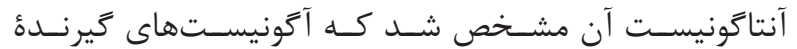

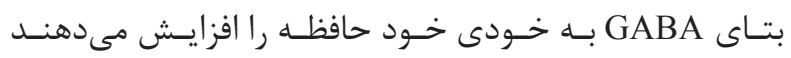

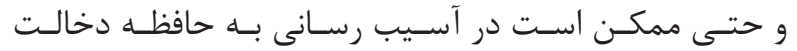

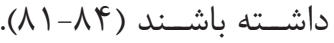

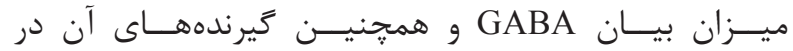

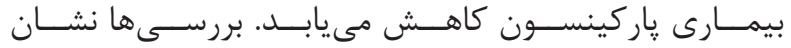

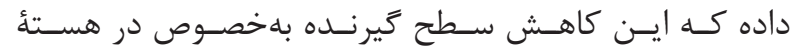

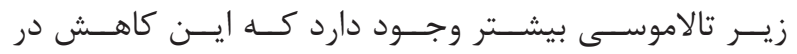

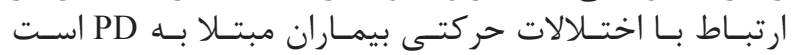

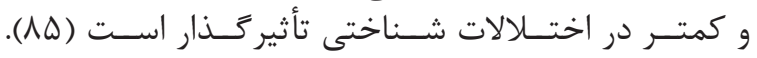

\section{ث) اختلال در برقرارى سينايس عصبى}

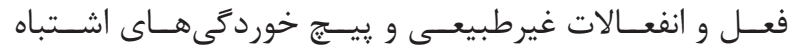

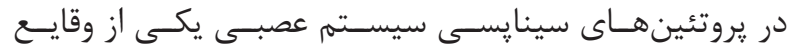

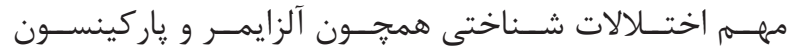

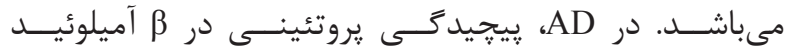

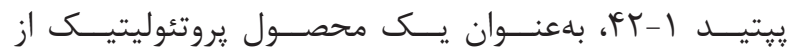

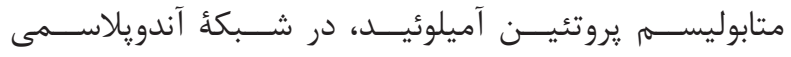

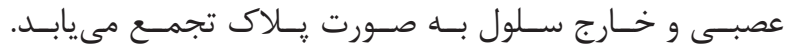

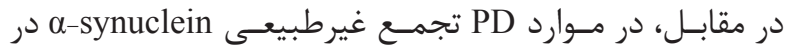

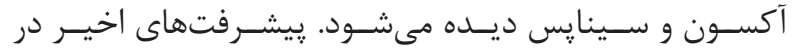

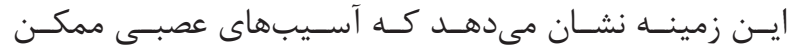

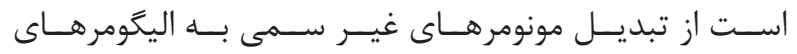

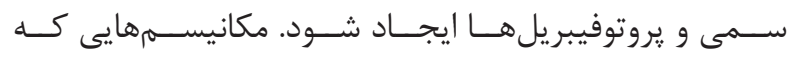

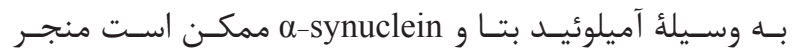

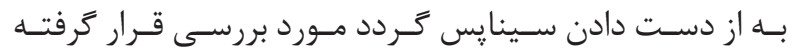

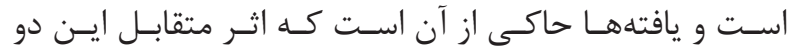

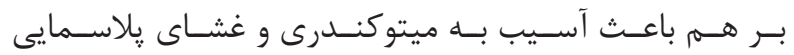

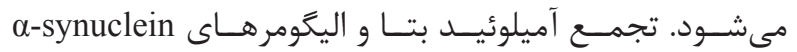

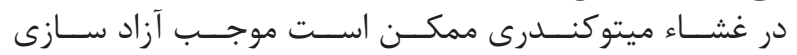

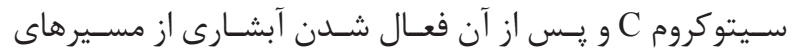

${ }^{46}$ Phosphoinositide 3-kinase

${ }^{47}$ Protein kinase B or Akt

${ }^{48}$ Protein tyrosine phosphatases

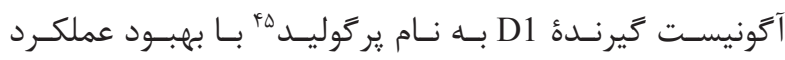

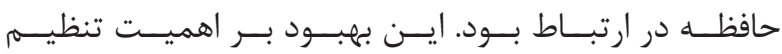

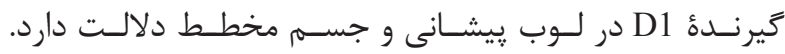

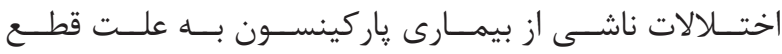

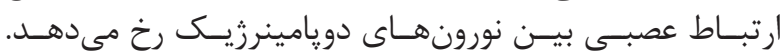

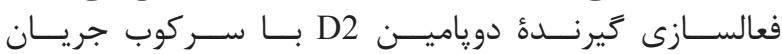

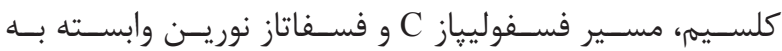

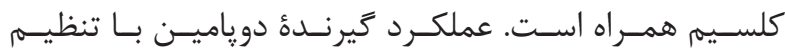

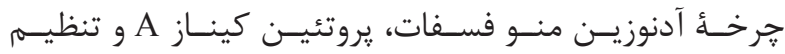

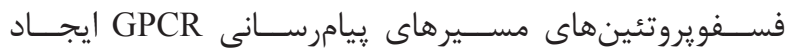

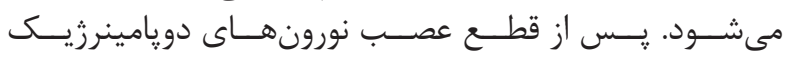

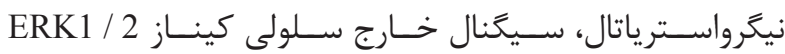

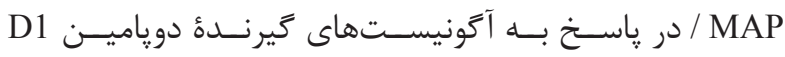

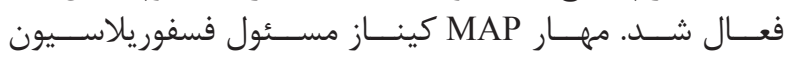

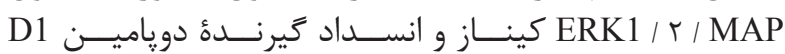

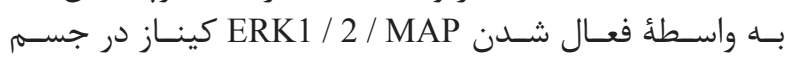

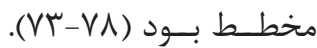

مطالعـات متعـدد داروهــاى دويامينرزيـــ بــا پاســخ ERK

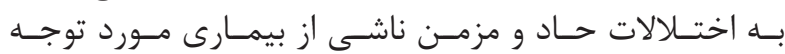

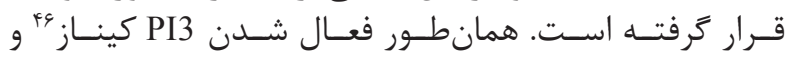

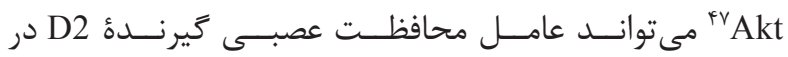

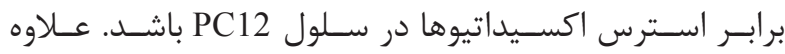

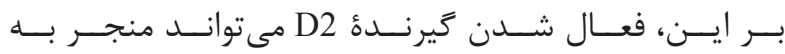

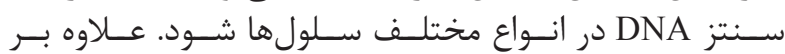

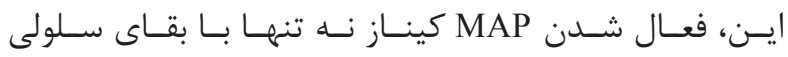

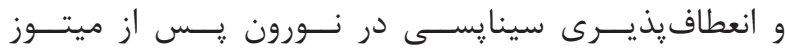

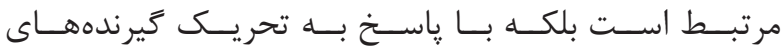

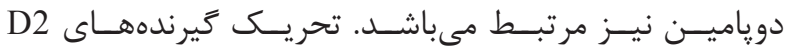

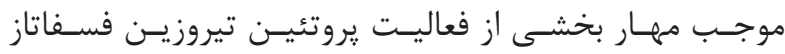

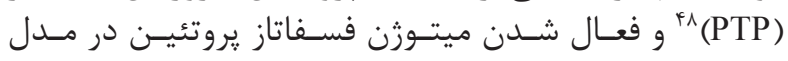

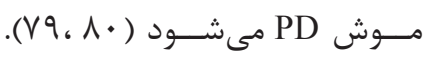

\section{GABA G- كيرندههاى}

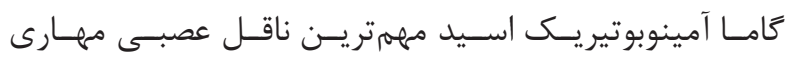

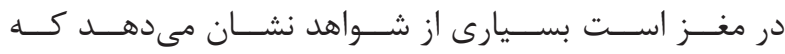

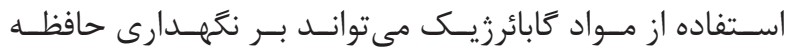

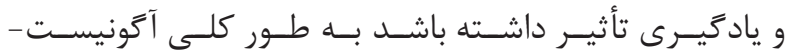

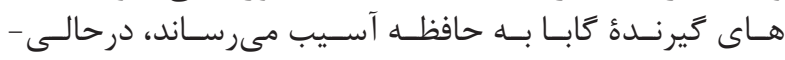

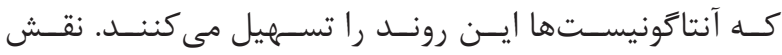

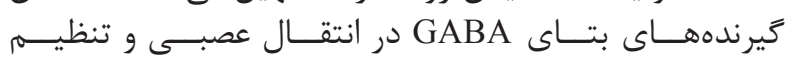

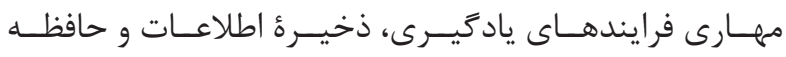

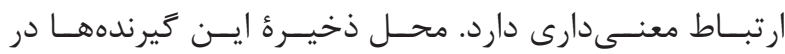

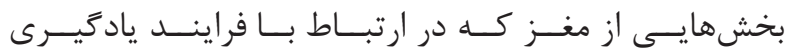

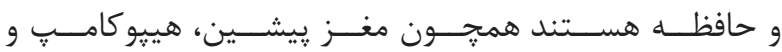

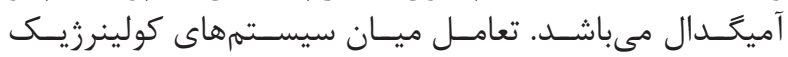

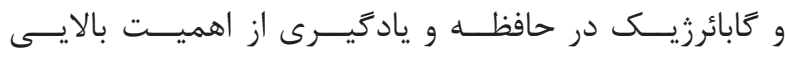

${ }^{49}$ Septal
${ }^{50}$ Medial wall 


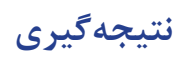

نقــش تغييــرات كيرنــده در سيســتم عصبــى مركــزى

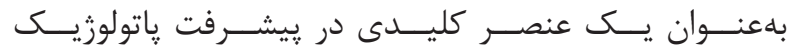

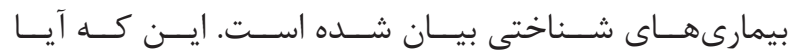

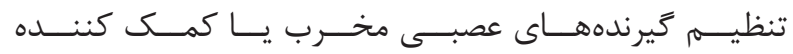

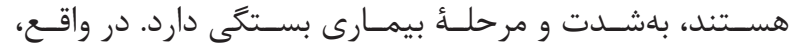

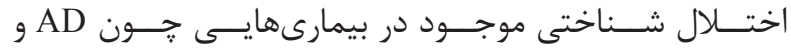

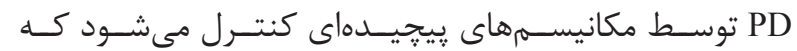

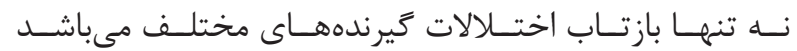

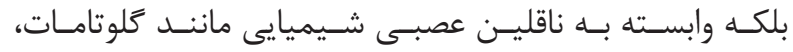

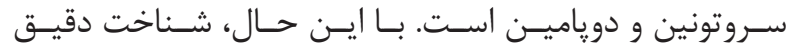

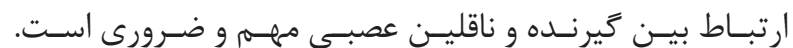

1. Guerrero A. Problem-based behavioral science of medicine. New York: Springer. pp. 2008; 367-79.

2. Petersen RC. Normal aging, mild cognitive impairment, and early Alzheimer's disease. Neurologist. 1995; 1: 1326-44.

3. Sedaghat F. May measuring of plasma amyloid beta in healthy subjects be used as a prognostic factor pointing to a risk of pending Alzheimer's disease? Shefaye Khatam. 2013; 1(2): 41-4.

4. Price JL, McKeel DW Jr, Buckles VD, Roe CM, Xiong C, Grundman M, et al. Neuropathology of nondemented aging: presumptive evidence for preclinical Alzheimer disease. Neurobiol Aging. 2009; 30 (7): 1026-36.

5. Babaei Abraki S, Chavoshi-Nezhad S. Alzheimer's disease: the effect of nrf2 signaling pathway on cell death caused by oxidative stress. Shefaye Khatam. 2015; 3 (1):145-56.

6. Hallett PJ, Standaert DG. Rationale for and use of NMDA receptor antagonists in parkinson's disease. Pharmacol Ther. 2004; 102(2): 155-74.

7. Tremblay C, Pilote M, Phivilay A, Emond V, Bennett DA, Calon F. Biochemical characterization of $A \beta$ and Tau pathologies in mild cognitive impairment and Alzheimer's disease. Journal of Alzheimer's Disease. 2007; 12 (4): 377-90.

8. Kato G, Agid Y. Acetylcholine receptors (author's transl). Nouv Presse Med. 1979; 8(29): 2407-11.

9. Paterson D, Nordberg A. Neuronal nicotinic receptors in the human brain. Prog Neurobiol. 2000; 61(1): 75-111.

10. Wang Q, Zengin A, Ying W, Newell KA, Wang

$$
\begin{aligned}
& \text { آيوزيتـوزى گَـردد. در مقابـل، اســترس اكســيداتيو و اختـلال در }
\end{aligned}
$$

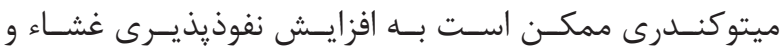

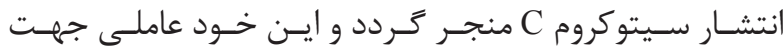

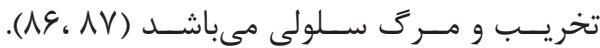

$$
\begin{aligned}
& \text { ت) كاهش سلولهاى عصبى }
\end{aligned}
$$

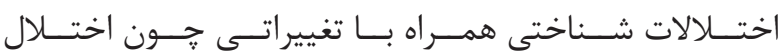

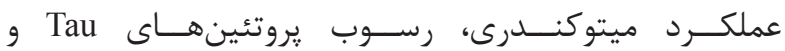

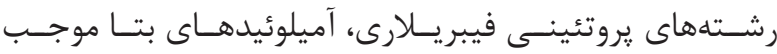

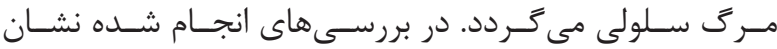

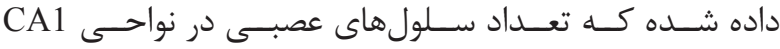

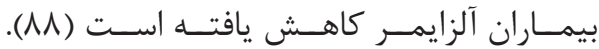

منابع

P, Yeo W, et al. Chronic treatment with simvastatin upregulates muscarinic M1/4 receptor binding in the rat brain. Neuroscience. 2008; 154 (3): 1100-6.

11. Miranda S, Opazo C, Larrondo LF, Muñ oz FJ, Ruiz F, Leighton F, et al. The role of oxidative stress in the toxicity induced by amyloid betapeptide in Alzheimer's disease. Prog Neurobiol. 2000; 62(6): 633-48.

12. Barrantes FJ, Borroni V, Valle' s S. Neuronal nicotinic acetylcholine receptor- cholesterol crosstalk in Alzheimer's disease. FEBS Lett. 2010; 584(9): 1856-63.

13. Medeiros R, Kitazawa M, Caccamo A, BagliettoVargas D, Estrada-Hernandez T, Cribbs DH, et al. Loss of muscarinic M(1) receptor exacerbates Alzheimer's disease-like pathology and cognitive decline. Am J Pathol. 2011; 179 (2): 980-91.

14. Tsang SW, Lai MK, Kirvell S, Francis PT, Esiri MM, Hope T, et al. Impaired coupling of muscarinic M1 receptors to G-proteins in the neocortex is associated with severity of dementia in Alzheimer's disease. Neurobiol Aging. 2006; 27 (9): 1216-23.

15. Poulin B, Butcher A, McWilliams P, Bourgognon JM, Pawlak R, Kong KC, et al. The M3-muscarinic receptor regulates learning and memory in a receptor phosphorylation/ arrestin-dependent manner. Proc Natl Acad Sci. 2010; 107(20): 9440-5.

16. Jones CK, Brady AE, Davis AA, Xiang Z, Bubser M, Tantawy MN, et al. Novel selective allosteric activator of the M1 muscarinic acetylcholine receptor regulates amyloid processing and produces antipsychotic-like activity in rats. Neuroscience. 2008; 28(41): 10422-33

17. Wevers A, Schroder H. Nicotinic acetylcholine receptors in Alzheimer's disease. J Alzheimers Dis. 
1999; 1(4-5): 207-19.

18. Perry EK, Perry RH, Smith CJ, Purohit D, Bonham J, Dick DJ, et al. Cholinergic receptors in cognitive disorders. Can J Neurol Sci. 1986; 13(4): 521-7.

19. Paterson D, Nordberg A. Neuronal nicotinic receptors in the human brain. Prog Neurobiol. 2000; 61(1): 75-111.

20. Sabbagh MN, Shah F, Reid RT, Sue L, Connor DJ, Peterson LK, et al. Pathologic and nicotinic receptor binding differences between mild cognitive impairment, Alzheimer disease, and normal aging. Arch Neurol. 2006; 63(12): 1771-6.

21. Sabri O, Kendziorra K, Wolf H, Gertz HJ, Brust P. Acetylcholine receptors in dementia and mild cognitive impairment. Eur J Nucl Med Mol Imaging. 2008; 35(1): S30-S45.

22. Ulas J, Brunner LC, Geddes JW, Choe W, Cotman CW. N-methyl-D-aspartate receptor complex in the hippocampus of elderly, normal individuals and those with Alzheimer's disease. Neuroscience. 1992; 49(1): 45-61.

23. Mitsis EM, Reech KM, Bois F, Tamagnan GD, Macavoy MG, Seibyl JP, et al. 123I-5-IA-85380 SPECT imaging of nicotinic receptors in Alzheimer disease and mild cognitive impairment. J Nucl Med. 2009; 50(9): 1455-63.

24. Ellis JR, Villemagne VL, Nathan PJ, Mulligan RS, Gong SJ, Chan JG, et al. Relationship between nicotinic receptors and cognitive function in early Alzheimer's disease: a 2-[18F]fluoro-A-85380 PET study. Neurobiol. Learn Mem. 2008; 90(2): 404-12.

25. Young JW, Crawford N, Kelly JS, Kerr LE, Marston $\mathrm{HM}$, Spratt C, et al. Impaired attention is central to the cognitive deficits observed in alpha 7 deficient mice. Eur Neuropsychopharmacol. 2007; (2): 145-55.

26. Shen JX, Yakel JL. Nicotinic acetylcholine receptormediated calcium signaling in the nervous system. Acta Pharmacol Sin. 2009; 30(6): 673-80.

27. Lilja AM, Porras O, Storelli E, Nordberg A, Marutle A. Functional interactions of fibrillar and oligomeric amyloidbeta with alpha7 nicotinic receptors in Alzheimer's disease. J Alzheimers Dis. 2011; 23(2): 335-47.

28. Laureys G, Clinckers R, Gerlo S, Spooren A, Wilczak $\mathrm{N}$, Kooijman R, et al. Astrocytic beta(2)-adrenergic receptors: from physiology to pathology. Prog Neurobiol. 2010; 91(3): 189-99.
29. Sharp SI, Ballard CG, Chen CP, Francis PT. Aggressive behavior and neuroleptic medication are associated with increased number of alphal-adrenoceptors in patients with Alzheimer disease. Am J Geriatr Psychiatr. 2007; 15(5): 435-7.

30. Yu JT, Tan L, Ou JR, Zhu JX, Liu K, Song JH, et al. Polymorphisms at the beta 2-adrenergic receptor gene influence Alzheimer's disease susceptibility. Brain Res. 2008; 1210; 216-22.

31. Shimohama S, Taniguchi T, Fujiwara M, Kameyama M, Biochemical characterization of alpha-adrenergic receptors in human brain and changes in Alzheimer-type dementia. J Neurochem. 1986; 47(4): 1295-301.

32. Kalaria RN, Andorn AC. Adrenergic receptors in aging and Alzheimer's disease: decreased alpha 2-receptors demonstrated by $[3 \mathrm{H}]$ p-aminoclonidine binding in prefrontal cortex. Neurobiol. Aging. 1991; 12(2): 131-6.

33. Meyer PM, Strecker K, Kendziorra K, Becker G, Hesse S, Woelpl D, et al. Reduced alpha4beta2-nicotinic acetylcholine receptor binding and its relationship to mild cognitive and depressive symptoms in parkinson disease Arch Gen Psychiatr. 2009; 66(8): 866-77.

34. Oishi N, Hashikawa K, Yoshida H, Ishizu K, Ueda M, Kawashima H, et al. Quantification of nicotinic acetylcholine receptors in parkinson's disease with (123) I-5IA SPECT. J Neurol Sci. 2007; 256(1-2): 52-60.

35. Szot P, White SS, Greenup JL, Leverenz JB, Peskind ER, Raskind MA. Compensatory changes in the noradrenergic nervous system in the locus ceruleus and hippocampus of postmortem subjects with Alzheimer's disease and dementia with Lewy bodies. J Neurosci. 2006; 26(2): 467-78.

36. Hoyer D, Martin G. 5-HT receptor classification and nomenclature: towards a harmonization with the human genome. Neuropharmacology.1997; 36(4-5): 419-28.

37. Lai MK, Tsang SW, Francis PT, Esiri MM, Hope T, Lai OF, et al. [3H]GR113808 binding to serotonin 5-HT(4) receptors in the postmortem neocortex of Alzheimer disease: a clinicopathological study. J Neural Transm. 2003; 110(7): 779-88.

38. Hasselbalch SG, Madsen K, Svarer C, Pinborg LH, Holm S, Paulson OB, et al. Reduced 5-HT2A receptor binding in patients with mild cognitive impairment. Neurobiol Aging. 2008; 29 (12): 1830-8.

39. Mitchell ES, Neumaier JF. 5-HT6 receptors: a novel target for cognitive enhancement. Pharmacol Ther. 2005; 108(3): 320-33. 
40. Inoue Y, Wagner Jr, Wong DF, Links JM, Frost JJ, Dannals RF, et al. Atlas of dopamine receptor images (PET) of the human brain. J Comput Assist Tomogr. 1985; 9(1): 129-40.

41. Meneses A, Hong E. 5-HT1A receptors modulate the consolidation of learning in normal and cognitively impaired rats. Neurobiol Learn Mem. 1999; 71(2): 207-18.

42. Nichols DE, Nichols CD. Serotonin receptors. Chem Rev. 2008; 108: 1614-41.

43. Truchot L, Costes N, Zimmer L, Laurent B, Le Bars D, Thomas-Antérion C, et al. A distinct [18F]MPPF PET profile in amnestic mild cognitive impairment compared to mild Alzheimer's disease. Neuroimage. 2008; 40(3):1251-6.

44. Upton N, Chuang TT, Hunter AJ, Virley DJ. 5-HT6 receptor antagonists as novel cognitive enhancing agents for Alzheimer's disease. Neurotherapeutics. 2008; 5(3): 458-69.

45. Hirst WD, Stean TO, Rogers DC, Sunter D, Pugh P, Moss SF, et al. SB-399885 is a potent, selective 5-HT6 receptor antagonist with cognitive enhancing properties in aged rat water maze and novel object recognition models. Eur J Pharmacol. 2006; 553(1-3): 109-19.

46. Schechter LE, Lin Q, Smith DL, Zhang G, Shan Q, Platt B, et al. Neuropharmacological profile of novel and selective 5-HT6 receptor agonists: WAY-181187 and WAY-208466. Neuropsychopharmacology. 2008; 33 (6): 1323-35.

47. West PJ, Marcy VR, Marino MJ, Schaffhauser H. Activation of the 5-HT(6) receptor attenuates long-term potentiation and facilitates GABAergic neurotransmission in rat hippocampus. Neuroscience. 2009; 164(2): 692-701.

48. Blin J, Baron JC, Dubois B, Crouzel C, Fiorelli M, Attar-Levy D, et al. Loss of brain 5-HT2 receptors in Alzheimer's disease. In vivo assessment with positron emission tomography and [18F] setoperone. Brain. 1993; 116 (3): 497-510.

49. Rosse G, Schaffhauser H. 5-HT6 receptor antagonists as potential therapeutics for cognitive impairment. Curr Top Med Chem. 2010; 10(2): 207-21.

50. Marie E, Hertz GL. Serotonin mediation of early memory formation via 5-HT2B receptor-induced glycogenolysis in the day-old chick. Front Pharmacol. 2014; 5(54). doi: 10.3389/fphar.2014.00054.
51. Yoshimi N, Fujita Y, Ohgi Y, Futamura T, Kikuchi T, Hashimoto K. Effects of brexpiprazole, anovel serotonindopamine activity modulator, onphencyclidineinducedcognitivedeficitsinmice: a rolefor serotonin 5-HT1A receptors. Pharmacol Biochem Behav. 2014; 124: 245-9.

52. Woehrle NS, Klenotich SJ, Jamnia N, Ho EV, Dulawa SC. Effects of chronic fluoxetine treatment on serotonin 1B receptor-induced deficits in delayed alternation. Psychopharmacology (Berl). 2013; 227: 545-51.

53. Harris KM, Sultan P. Variation in the number, location and size of synaptic vesicles provides an anatomical basis for the nonuniform probability of release at hippocampal CA1 synapses. Neuropharmacology. 1995; 34 (11): 1387-95.

54. Xiong H, McCabe L, Costello J, Anderson E, Weber G, Ikezu T. Activation of NR1a/NR2B receptors by soluble factors from APP-stimulated monocytederived macrophages: implications for the pathogenesis of Alzheimer's disease. Neurobiol Aging. 2004; 25(7): 905-11.

55. Gulya' s B, Pavlova E, Ka' sa P, Gulya K, Bakota L. Activated MAO-B in the brain of Alzheimer patients, demonstrated by [11C]-L-deprenyl using whole hemisphere autoradiography. Neurochem Int. 2011; 58(1): $60-8$.

56. Kurup $\mathrm{P}$, Zhang $\mathrm{Y}, \mathrm{Xu} \mathrm{J}$, Venkitaramani DV, Haroutunian V, Greengard P, et al. Abeta-mediated NMDA receptor endocytosis in Alzheimer's disease involves ubiquitination of the tyrosine phosphatase STEP61. J Neurosci. 2010; 30(17): 5948-57.

57. Decker H, Jurgensen S, Adrover MF, BritoMoreira J, Bomfim TR, Klein WL, et al. N-methylDaspartate receptors are required for synaptic targeting of Alzheimer's toxic amyloid-beta peptide oligomers. J Neurochem. 2010; 115(6): 1520-9.

58. De Felice FG, Velasco PT, Lambert MP, Viola K, Fernandez SJ, Ferreira ST, et al. Abeta oligomers induce neuronal oxidative stress through an N-methyl-Daspartate receptor-dependent mechanism that is blocked by the Alzheimer drug memantine. J Biol Chem. 2007; 282(15): 11590-601.

59. Aligholi H, Safahani M, Sarkaki A, Amani R. Protective effect of soy on movement disorders induced by Parkinson disease in ovariectomized animal model. Shefaye Khatam. 2013; 1(3): 5-10.

60. Wenthold RJ, Roche KW. The organization and regulation of non-NMDA receptors in neurons. Prog 
Brain Res. 1998; 116: 133-52.

61. Setiawan E1, Jackson MF, MacDonald JF, Matthews SG. Effects of repeated prenatal glucocorticoid exposure on long-term potentiation in the juvenile guinea-pig hippocampus. J Physiol. 2007; 581(3): 1033-42.

62. Sacktor B, Rosenbloom IL, Liang CT, Cheng L. Sodium gradient- and sodium plus potassium gradientdependent L-glutamate uptake in renal basolateral membrane vesicles. J Membr Biol. 1981; 60(1): 63-71.

63. Mietelska-Porowska A, Wasik U, Goras M, Filipek A, Niewiadomska G.Tau protein modifications and interactions: their role in function and dysfunction. Int J Mol Sci. 2014; 15(3): 4671-713.

64. Pisano P, Samuel D, Nieoullon A, Kerkerian-Le Goff L. Activation of the adenylate cyclase-dependent protein kinase pathway increases high affinity glutamate uptake into rat striatal synaptosomes. Neuropharmacology. 1996; 35(5): 541-7.

65. Plachez C, Danbolt NC, Recasens M. Transient expression of the glial glutamate transporters GLAST and GLT in hippocampal neurons in primary culture. J Neurosci Res. 2000; 59(5): 587-93.

66. Fykse EM, Iversen EG, Fonnum F. Inhibition of L-glutamate uptake into synaptic vesicles. Neurosci Lett. 1992; 135(1): 125-8.

67. Galli A, Blakely RD, Defelice LJ. Norepinephrine transporters have channel modes of conduction. Proc Natl Acad Sci USA. 1996; 93(16): 8671-6.

68. Pizzolato G, Chierichetti F, Fabbr M, Cagnin A, Dam M, Ferlin G, et al. Reduced striatal dopamine receptors in Alzheimer's disease: single photon emission tomography study with the D2 tracer [123I] -IBZM. Neurology. 1996; 47(4): 1065-8.

69. Kemppainen N, Laine M, Laakso MP, Kaasinen V, Nagren K, Vahlberg T, et al. Hippocampal dopamine D2 receptors correlate with memory functions in Alzheimer's disease. Eur J Neurosci. 2003; 18(1): 149-54.

70. $\mathrm{Pe}^{\prime}$ ron J, Vicente S, Leray E, Drapier S, Drapier $\mathrm{D}$, Cohen R, et al. Are dopaminergic athways involved in theory of mind? a study in Parkinson's disease. Neuropsychologia. 2009; 47(2): 406-14.

71. Fetsko LA, Xu R, Wang Y. Effects of age and dopamine D2L receptordeficiency n motor and learning functions. Neurobiol Aging. 2005; 26(4): 521-30.

72. Wang Q, Wang PH, McLachlan C, Wong PT.
Simvastatin reverses the downregulation of dopamine D1 and D2 receptor expression in the prefrontal cortex of 6-hydroxydopamine-induced Parkinsonian rats. Brain Res. 2005; 1045(1-2): 229-33.

73. Wang Q, Ting WL, Yang H, Wong PT. High doses of simvastatin upregulate dopamine D1 and D2 receptor expression in the rat prefrontal cortex: possible involvement of endothelial nitric oxide synthase. Br J Pharmacol. 2005; 144(7): 933-9.

74. Boileau I, Guttman M, Rusjan P, Adams JR, Houle $\mathrm{S}$, Tong $\mathrm{J}$, et al. Decreased binding of the D3 dopamine receptor-preferring ligand [11C]- $(+)-\mathrm{PHNO}$ in drugnaive Parkinson's disease. Brain. 2009; 132(5): 1366-75.

75. Turle-Lorenzo N, Maurin B, Puma C, Chezaubernard $\mathrm{C}$, Morain $\mathrm{P}$, Baunez $\mathrm{C}$, et al. The dopamine agonist piribedil with L-DOPA improves attentional dysfunction: relevance for Parkinson's disease. J Pharmacol Exp Ther. 2006; 319(2): 914-23.

76. Costa A, Peppe A, Dell'Agnello G, Caltagirone C, Carlesimo GA. Dopamine and cognitive functioning in de novo subjects with Parkinson's disease: effects of pramipexole and pergolide on working memory. Neuropsychologia. 2009; 47(5): 1374-81.

77. Sun H, Zhang J, Zhang L, Liu H, Zhu H, Yang Y. Environmental enrichment influences BDNF and NR1 levels in the hippocampus and restores cognitive impairment in chronic cerebral hypoperfused rats. Curr Neurovasc Res. 2010; 7(4): 268-80.

78. Fetsko LA, Xu R, Wang Y. Effects of age and dopamine D2L receptordeficiency on motor and learning functions. Neurobiol Aging. 2005; 26(4): 521-30.

79. Gerfen CR, Miyachi S, Paletzki R, Brown P. D1 dopamine receptor supersensitivity in the dopaminedepleted striatum results from a switch in the regulation of ERK1/2/MAP kinase. J Neurosci. 2002: 22(12): 5042-54.

80. Zhen X, Torres C, Cai G, Friedman E. Inhibition of protein tyrosine/ mitogen-activated protein kinase phosphatase activity is associated with D2 dopamine receptor supersensitivity in a rat model of Parkinson's disease. Mol Pharmacol. 2002: 62(6): 1356-63.

81. Perego C, Vanoni C, Villa A, Longhi R, Kaech SM, Frohli E, et al. PDZ-mediated interactions retain the epithelial GABA transporter on the basolateral surface of polarized epithelial cells. EMBO J. 1999; 18(9): 2384-93.

82. Jensen JB, Pickering DS, Schousboe A. Depolarization-induced release of [3H]D-aspartate from 
GABAergic neurons caused by reversal of glutamate transporters. Int J Dev Neurosci. 2000;18(2-3): 309-15.

83. Kanner BI. Active transport of gamma-aminobutyric acid by membrane vesicles isolated from rat brain. Biochemistry. 1978; 17(7): 1207-11.

84. Kanner BI. Solubilization and reconstitution of the gammaaminobutyric acid transporter from rat brain. FEBS Lett. 1978; 89(1): 47-50.

85. Hansson E, Ro“nnba“ck L. Receptor regulation of the glutamate, GABA and taurine high-affinity uptake into astrocytes in primary culture. Brain Res. 1991; 548(1-2): 215-21.
86. Scheff SW, Price DA, Schmitt FA, Mufson EJ. Hippocampal synaptic loss in early alzheimer' disease and mild cognitive impairment. Neurobiol Aging. 2006; 27 (10): 1372-84.

87. Schmidt ML, DiDario AG, Otvos L Jr, et al. Plaqueassociated neuronal proteins: a recurrent motif in neuritic amyloid deposits throughout diverse cortical areas of the Alzheimer's disease brain. Exp Neurol. 1994; 130 (2): 311-22.

88. Gomez-Isla T, Price JL, McKeel DW Jr, et al. Profound loss of layer II entorhinal cortex neurons occurs in very mild alzheimer's disease. J Neurosci. 1996; 16 (14): 4491-500. 